\title{
Fundamental Investigation of Fuel Transformations in Pulverized Coal Combustion and Gasification Technologies
}

\section{Technical Progress}

Report for the Period: September 1, 2001 - August 31, 2002

Principal Authors: $\quad$ Robert Hurt, Brown University

Joseph Calo, Brown University

Thomas Fletcher, Brigham Young University

Alan Sayre, McDermott Technologies Inc.

Report Issue Date: January 2003

DOE Award Number: $\quad$ DE-FG26-OONT40815

Submitting Organization: Brown University

Division of Engineering, Box D

Providence, RI 02912 


\section{Disclaimer}

This report was prepared as an account of work sponsored by an agency of the United States Government. Neither the United States Government nor any agency thereof, nor any of their

employees, makes any warranty, express of implied, or assumes any legal liability or responsibility for the accuracy, completeness, or usefulness of any information, apparatus, product, or process disclosed, or represents that its use would not infringe privately owned rights. Reference herein to any specific commercial product, process, or service by trade name, trademark, manufacturer, or otherwise does not necessarily constitute or imply its endorsement, recommendation, or favoring by the United States Government or any agency thereof. The views and opinions of authors expressed herein do not necessarily state or reflect those of the United States Government or any agency thereof. 


\section{TABLE OF CONTENTS}

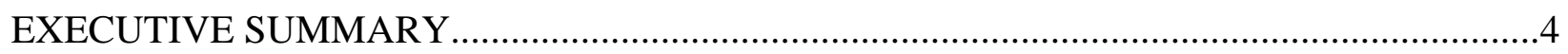

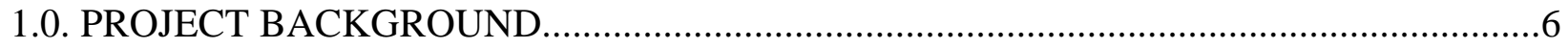

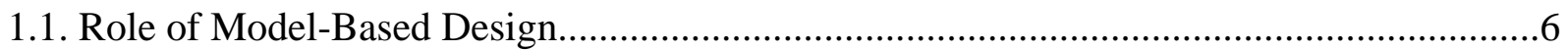

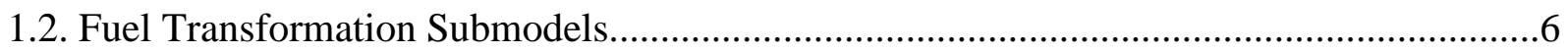

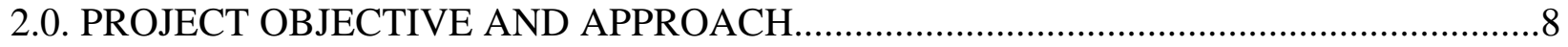

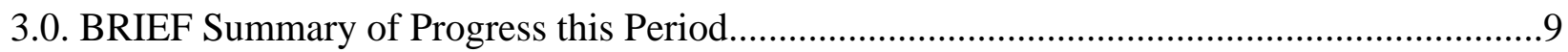

4.0. Detailed Discussions of Progress in selected areas................................................................10

4.1. Char Combustion Reactivities for a Suite of Diverse Solid Fuels and Char-Forming........10

Organic Model Compound Chars...............................................................................................

4.1 -1. Introduction and Background.................................................................................10

4.1-2. Materials and Experimental Procedures................................................................. 10

Table 1. Sample Suite of Solid Fuels and Organic Model Substances:

Properties and Char Reactivities...........................................................................12

4.1-3. Definitions of Standard Reactivity Indices.............................................................13

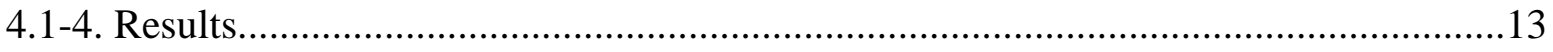

4.1-5. Reactivity / Property Relations...................................................................................15

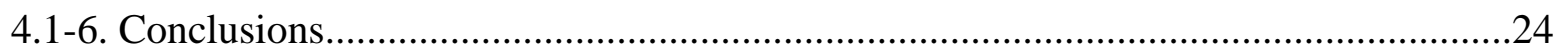

4.2. High Pressure Coal Combustion Studies at BYU..........................................................25

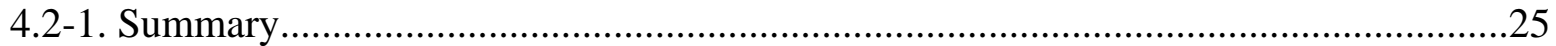

4.2-2. Development of High-Pressure Flat-Flame-Burner.................................................25

4.2-3. Oxidation Kinetics of HPDT Char.............................................................................

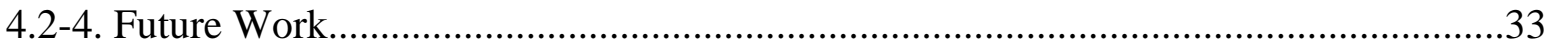

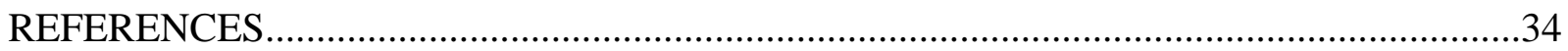




\section{EXECUTIVE SUMMARY}

The goal of this project is to carry out the necessary experiments and analyses to extend leading submodels of coal transformations to the new conditions anticipated in next-generation energy technologies. During the first project quarter, a technical kick-off meeting was held on the Brown campus involving PIs from Brown (Hurt, Calo), BYU (Fletcher), and B\&W (Sayre, Burge). Following this first meeting the current version of CBK (Version 8) was transferred to B\&W McDermott and the HP-CBK code developed by BYU was transferred to Brown to help guide the code development in this project. Also during the first project year, progress was reviewed at an all-hands meeting was held at Brigham Young University in August, 2001. The meeting was attended by PIs Fletcher, Hurt, Calo, and Sayre, and also by affiliated investigators Steven Burge from McDermott and Prof. William Hecker from BYU. During the first project year, significant progress was made on several fronts, as described in detail in the previous annual report.

In the current second annual report, we report on progress made on two important project tasks. At Brown University:

(1) Char combustion reactivities at $500^{\circ} \mathrm{C}$ in air were determined for a diverse set of solid fuels and organic model compound chars. These varied over 4 orders of magnitude for the chars prepared at $700^{\circ} \mathrm{C}$, and over 3 orders of magnitude for the chars prepared at $1000^{\circ} \mathrm{C}$. The resultant reactivities correlate poorly with organic elemental composition and with char surface area.

(2) Specially-acquired model materials with minute amounts of inorganic matter exhibit low reactivities that fall in a narrow band as a function of wt-\% carbon. Reactivities in this sample subset correlate reasonably well with total char surface area.

(3) A hybrid chemical/statistical model was developed which explains most of the observed reactivity variation based on four variables: the amounts of nano-dispersed $\mathrm{K}$, nanodispersed $(\mathrm{Ca}+\mathrm{Mg})$, elemental carbon (wt-\% daf), and nano-dispersed vanadium, listed in decreasing order of importance. Catalytic effects play a very significant role in the oxidation of most practical solid fuel chars. Some degree of reactivity estimation is possible using only elemental analyses of parent fuels, but only if correlative techniques 
make use of the existing body of knowledge on the origin, form and dispersion of inorganic matter in various fuel classes.

During the past year at BYU, work focused primarily on renovation of the BYU high pressure drop tube reactor (HPDT). This work has included design and testing of a flat-flameburner that can be operated at high pressure. A high-temperature, high-pressure gas profile has been achieved within this high-pressure flat-flame burner (HP-FFB). Detailed descriptions of the design and testing of the HP-FFB are given in this report. In addition, continued char reactivity experiments in the high pressure thermogravimetric analyzer (HP-TGA) have been performed on chars produced at different pressures in the HPDT. Results of the HP-TGA reactivity studies on a high-volatile A bituminous (Pittsburgh \#8) char are that intrinsic char activation energy increases with pyrolysis pressure, and that the oxygen order is roughly 0.9. These results are different than previous research on chars produced at atmospheric pressure. These new data show that the rate constant decreases with increasing pyrolysis pressure. However, the hydrogen content of the new chars produced at elevated pressures was fairly high ( 2 wt. \%, daf), and char samples produced at higher temperatures are desired.

During the next project year, experimental work on oxygen reactivity at high pressure will continue at $\mathrm{BYU}$, and on $\mathrm{CO}_{2}$ reactivity at high pressure at Brown University. Selected chars produced at BYU under high pressure conditions will also be used at Brown for reactivity studies. 


\subsection{PROJECT BACKGROUND}

Increased concern over global warming is currently motivating a major research effort in the U.S. on future energy technologies with low $\mathrm{CO}_{2}$ emissions. Research is needed to configure and design future coal-fired power-generation technologies with no or minimum impact on atmospheric $\mathrm{CO}_{2}$ concentrations. A reduction in $\mathrm{CO}_{2}$ emissions can be accomplished in the near term through increased efficiency with existing systems. Integrated gasification combined cycle (IGCC) systems have been used as the starting point for strategies to reduce $\mathrm{CO}_{2}$ in the atmosphere, since (a) they are more efficient than conventional systems (50-60\% as opposed to the current 34\%) and (b) they promise to provide a concentrated stream of $\mathrm{CO}_{2}$ by using steam and pure $\mathrm{O}_{2}$ as the gasification agents (without $\mathrm{N}_{2}$ as a diluent). Sequestration processes are currently under development that rely on IGCC, but this technology has not yet been widely demonstrated. In addition to IGCC, systems, combustion systems operating with enhanced oxygen concentration or pressure may also provide concentrated $\mathrm{CO}_{2}$ streams.

\subsection{Role of Model-Based Design.}

Within the last several years computational fluid dynamics (CFD) has firmly established itself as an important tool for the design, optimization, and retrofit analysis of full-scale combustion furnaces. CFD tools, when expertly applied, can identify firing configurations that significantly enhance performance and avoid the need for full-scale testing. Computer simulation is even more important for the design and development of next generation energy technologies based on oxygen-enriched combustion and/or gasification. These advanced systems cannot be reliably designed in an evolutionary way, as is often the case with current technologies, since there is no extensive database of operating experience with similar units. Model based design requires fuel-general submodels of coal transformations that are accurate under the combustion and gasification conditions unique to these processes.

\subsection{Fuel Transformation Submodels.}

Successful furnace simulation requires predictive capabilities for many subprocesses including fuel transformation submodels to predict: (1) pyrolysis and char yield, (2) char oxidation and carbon burnout, (3) nitrogen release, and (3) mineral transformations. One of the PIs, (T. Fletcher) is the primary architect of the chemical percolation devolatilization (CPD) model (Fletcher et al. 1992), a mechanistic pyrolysis model based on a network description of the 
chemical structure of the parent coal. The model: (a) is suitable for application in large comprehensive models of coal combustion, and (b) accurately describes key chemical structural features and reaction mechanisms of coal. Another of the Principal Investigators (R. Hurt) been engaged over the last eight years at the Combustion Research Facility at Sandia National Laboratories and at Brown University in the development of advanced submodels for char combustion, with emphasis on carbon burnout prediction. Carbon burnout has become a critical issue in the existing boiler stock as low-NOx burner retrofits have increased carbon carryover and seriously impacted ash utilization markets at many sites in the U.S.. The experimental work has led to the Carbon Burnout Kinetic Model (CBK), a fuel-general kinetics package designed to predict carbon burnout under conditions relevant to current pulverized coal-fired boilers [Hurt et al., 1998]. Special emphasis is given to the late stages of combustion, which exert a strong influence on the burnout process that determines the carbon content of ash and thus ash utilization options [Hurt, 1998].

The fuel submodels listed above have been developed and applied for atmospheric pc-fired combustion systems. In this application they have found practical use in industry codes and have demonstrated some predictive capability, but further validation against field data is needed, as is extension to conditions found in next-generation energy processes. Although many of the condensed phase processes (internal diffusion, thermal annealing) can be directly carried over into models of gasification and $\mathrm{O}_{2}$-enriched combustion, other reaction processes in the condensed phases require new data to make predictions under these conditions. Specifically new data is needed on: (1) the char formation process at high pressure, (2) char surface kinetics in enhanced oxygen and in the complex gasification environments, (3) nitrogen and inorganic release at high pressure and the concomitant high particle temperatures of enhanced oxygen combustion and oxygen-blown gasification systems, and (4) the development of engineering models that combine char property prediction with simplified surface kinetics for inclusion in practical flame codes. 


\subsection{PROJECT OBJECTIVE AND APPROACH}

The basic project objective is to carry out the necessary experiments and analyses to extend leading submodels of coal transformations to the new conditions anticipated in next-generation energy technologies. The work will use a combination of high-pressure TGA, atmospheric entrained flow reactor experiments, and experiments with a high pressure drop tube furnace to address volatile release, nitrogen release, inorganic release, and char properties and reactivity, with particular emphasis on gasification environments under pressure and enhanced oxygen environments at atmospheric pressure. The CPD and CBK models will be validated against fullscale data on current pc-technologies with industry involvement (McDermott / B\&W ) and will be extended to the new conditions using the data generated in the experimental portion of the program.

To achieve the above project objective, a multi-university/joint industry team has been assembled, consisting of Brown University (PIs Robert Hurt and Joseph Calo), Brigham Young University (PI Thomas Fletcher), and McDermott's Babcock and Wilcox Power Generation Group (PI Alan Sayre). The research work HAS BEEN divided into the following four tasks, with the participants indicated:

Task 1: Char Formation and Inorganic Release in High-Temperature Pressurized Flows (Fletcher, BYU)

Task 2: Combustion Kinetics in Environments with Elevated $\mathrm{O}_{2}$ and $\mathrm{CO}_{2}$ (R. Hurt, Brown)

Task 3: Gasification Kinetics in Pressurized $\mathrm{CO}_{2}$ (Calo, Brown; Fletcher, BYU)

Task 4: Validation and Extension of CPD and CBK Fuel Submodels (Sayre, B\&W; Fletcher, BYU; Hurt, Brown) 


\subsection{BRIEF SUMMARY OF PROGRESS THIS PERIOD}

Significant progress was made during the second year, as described in detail in Section 4.0 below. In summary:

At Brown University, char combustion reactivities at $500^{\circ} \mathrm{C}$ in air were determined for a diverse set of solid fuels and organic model compound chars. These varied over 4 orders of magnitude for the chars prepared at $700^{\circ} \mathrm{C}$, and over 3 orders of magnitude for the chars prepared at $1000^{\circ} \mathrm{C}$. The resultant reactivities correlate poorly with organic elemental composition and with char surface area. Specially-acquired model materials with minute amounts of inorganic matter exhibit low reactivities that fall in a narrow band as a function of wt- $\%$ carbon. Reactivities in this sample subset correlate reasonably well with total char surface area. A hybrid chemical/statistical model was developed which explains most of the observed reactivity variation based on four variables: the amounts of nano-dispersed $\mathrm{K}$, nano-dispersed $(\mathrm{Ca}+\mathrm{Mg})$, elemental carbon (wt-\% daf), and nano-dispersed vanadium, listed in decreasing order of importance. Catalytic effects play a very significant role in the oxidation of most practical solid fuel chars. Some degree of reactivity estimation is possible using only elemental analyses of parent fuels, but only if correlative techniques make use of the existing body of knowledge on the origin, form and dispersion of inorganic matter in various fuel classes.

During the past year at BYU, work focused primarily on renovation of the BYU high pressure drop tube reactor (HPDT). This work has included design and testing of a flat-flameburner that can be operated at high pressure. A high-temperature, high-pressure gas profile has been achieved within this high-pressure flat-flame burner (HP-FFB). Detailed descriptions of the design and testing of the HP-FFB are given in this report. In addition, continued char reactivity experiments in the high pressure thermogravimetric analyzer (HP-TGA) have been performed on chars produced at different pressures in the HPDT. Results of the HP-TGA reactivity studies on a high-volatile A bituminous (Pittsburgh \#8) char are that intrinsic char activation energy increases with pyrolysis pressure, and that the oxygen order is roughly 0.9 . These results are different than previous research on chars produced at atmospheric pressure. These new data show that the rate constant decreases with increasing pyrolysis pressure. However, the hydrogen content of the new chars produced at elevated pressures was fairly high ( 2 wt. $\%$, daf), and char samples produced at higher temperatures are desired. 


\subsection{DETAILED DISCUSSIONS OF PROGRESS IN SELECTED AREAS}

\subsection{Char Combustion Reactivities for a Suite of Diverse Solid Fuels and Char-Forming Organic Model Compound Chars.}

\section{1 -1. Introduction and Background}

Concern over the potential effects of global warming is driving a diversification in solid fuel selection - a shift from almost sole reliance on coal to a broader fuel mix encompassing organic matter of quite diverse origin and composition. To support this effort, comparative studies are needed in which large sets of these diverse alternate fuels are burned under standard conditions chosen to reveal intrinsic fuel-to-fuel differences in each of the fundamental combustion subprocesses: pyrolysis, char oxidation, mineral transformations, and pollutant formation.

For coals, the char combustion subprocess has been extensively studied and reviewed [1-4], and the major reactivity trends have been established through comparative studies employing a range of coals, including studies below $1000 \mathrm{~K}[5-8]$ and at flame temperatures $[9,10]$. There are no comparable studies on large sets of alternate fuels, although the recent literature does contain valuable information on individual fuels [11-14] or small sets of fuels of interest in a particular region [15-18]. It is not known if any of the compositional trends and correlations derived from coal studies have relevance to biomass and other alternate fuel types.

The goal of the present work was to measure char combustion reactivities for a large set of traditional and alternative solid fuels under standardized low-temperature conditions, free from the influence of mass- and heat-transfer processes (Zone I). A secondary goal was to identify possible quantitative relationships between char reactivity and parent fuel properties. To gain a deeper understanding of the origin of char reactivity in this data set, the sample suite was augmented by a series of char-forming chemical reagents and model materials that are nearly free of the inorganic contamination that is ubiquitous in practical solid fuels.

\section{1-2. Materials and Experimental Procedures}

A suite of 31 materials was assembled for this study (see Table 1), including 20 solid fuels and 11 organic model materials chosen for their low levels of potentially catalytic inorganic matter. Each of the 31 raw materials was pyrolyzed in a benchtop tube furnace at $700^{\circ} \mathrm{C}$ for 1 hour using a thin bed of sample spread in an oblong alumina boat, purged with flowing highpurity helium $(600 \mathrm{cc} / \mathrm{min})$. Seventeen of the raw materials were also pyrolyzed at $1000^{\circ} \mathrm{C}$ for 1 
hour to investigate the effect of heat treatment temperature. The subsequent chars were crushed and sieved to obtain a 75-106 $\mu \mathrm{m}$ size fraction for study. Because of the enormous reactivity range within this sample suite (over four orders of magnitude), it is not practical to measure all reactivities at a common temperature. Non-isothermal thermogravimetric analysis (TGA) was therefore carried out using a Cahn TG-2141 apparatus fed with dry air (21\% oxygen) at 40 $\mathrm{cc} / \mathrm{min}$ and atmospheric pressure. Char samples of 3-10 mg were spread as a thin bed on a platinum pan to avoid mass- and heat-transfer effects. Time, sample temperature, and mass were continuously recorded as the sample temperature was raised first to $105^{\circ} \mathrm{C}$ to drive off any moisture, then at $7 \mathrm{~K} / \mathrm{min}$ to $950^{\circ} \mathrm{C}$, at which point complete burnout was achieved for all samples. All reactivity measurements were made in triplicate and the mean values reported.

A subset of 14 of the $700^{\circ} \mathrm{C}$ chars was chosen for surface area measurements. Some fresh (unreacted) chars exhibit strong molecular sieving behavior in which the nitrogen and carbon dioxide surface areas are grossly different, an effect that is typically eliminated by only slight oxidative conversion $[19,20]$. For such chars, the proper assignment of area is ambiguous and the nitrogen area of the fresh char may be not at all representative of its values during most of the burnout process. To avoid this problem, chars slated for vapor adsorption measurements were first partially reacted by slow air oxidation in a tube furnace to conversions from $15-35 \%$ close to the $20 \%$ at which the reactivity indices were derived (see below). Each of these chars was outgassed for 20 hours at $300^{\circ} \mathrm{C}$, followed by measurement of 80 -point vapor adsorption isotherms in nitrogen at $77 \mathrm{~K}$ and in carbon dioxide at $195 \mathrm{~K}$, from which surface areas were computed using the BET theory. 


\section{Table 1. Sample Suite of Solid Fuels and Organic Model Substances: Propertiesb and Char Reactivities}

\begin{tabular}{|c|c|c|c|c|c|c|c|c|c|c|c|c|c|c|c|c|c|c|c|c|c|}
\hline Sample & ash & dry $\%$ & $\begin{array}{c}\mathrm{C} \\
\text { daf } \%\end{array}$ & $\begin{array}{c}\text { H } \\
\text { daf } \%\end{array}$ & $\begin{array}{c}0 \\
\text { daf } \%\end{array}$ & $\begin{array}{c}\mathbf{N} \\
\text { daf } \%\end{array}$ & $\begin{array}{c}\mathrm{S} \\
\text { daf } \%\end{array}$ & $\begin{array}{c}\text { Al } \\
\text { ppmw }\end{array}$ & ppmw & ppmw & ppmw & ppmw & ppmw & ppmw & ppmw & ppmw & $\begin{array}{c}\mathbf{N}_{2} \\
\mathbf{A r e a}^{2} \\
\mathbf{m}^{2} / \mathrm{g}\end{array}$ & $\begin{array}{c}\mathrm{CO}_{2} \\
\mathrm{Area}^{\mathrm{c}} \\
\mathrm{m}^{2} / \mathrm{g}\end{array}$ & $\begin{array}{c}\mathbf{T}_{\mathbf{c r}} \mathrm{j} \\
\mathbf{K}\end{array}$ & $\begin{array}{c}\log _{10} R^{f} \\
700^{\circ} \mathrm{C} \\
\sec ^{-1}\end{array}$ & $\begin{array}{c}\log _{10} R^{\mathrm{f}} \\
1000^{\circ} \mathrm{C} \\
\sec ^{-1}\end{array}$ \\
\hline $\begin{array}{l}\text { Microcrystalline } \\
\text { Cellulose }\end{array}$ & 0.05 & 90.71 & 41.86 & 6.42 & 51.68 & 0.02 & 0.02 & $<10$ & $<5$ & $<10$ & $<40$ & $<10$ & 59 & $<1$ & 12 & $<1$ & 547.0 & 645.1 & 900 & -4.35 & -4.91 \\
\hline Synthetic RDF & 19.84 & 71.324 & 41.95 & 6.46 & 51.55 & 0.02 & 0.02 & $\begin{array}{c}2360 \\
0\end{array}$ & 120 & 74 & $<40$ & 44 & 253 & 1 & $\begin{array}{c}6240 \\
0\end{array}$ & $<1$ & 335.5 & 5353.3 & 905 & -4.41 & -4.84 \\
\hline $\begin{array}{l}\text { Sucrose, } \mathrm{C}_{12} \mathrm{H}_{22} \mathrm{O}_{7} \\
\text { a }\end{array}$ & - & - & 42.08 & 6.50 & 51.40 & $<0.01<$ & $<0.01$ & $<100$ & $<100$ & $<100$ & $<100$ & $<100$ & $<100$ & $<100$ & $<100$ & $<50$ & 592.1 & 1638.0 & 900 & -4.35 & -4.58 \\
\hline Dried Sludge & 0.06 & 76.36 & 42.37 & 6.54 & 48.01 & 3.05 & 0.03 & 67 & 983 & 289 & 480 & 218 & 452 & $<1$ & 256 & $<1$ & - & - & 838 & -3.48 & - \\
\hline Corn Stalk & 3.24 & 74.77 & 43.99 & 6.28 & 48.93 & 0.70 & 0.09 & 106 & 1900 & 130 & $\begin{array}{c}1530 \\
0\end{array}$ & 1600 & 41 & $<1$ & 2380 & $<1$ & 213.5 & 5327.1 & 701 & -1.70 & -2.67 \\
\hline Wheat Straw & 9.43 & 68.76 & 44.23 & 6.39 & 48.63 & 0.60 & 0.15 & 70 & 1720 & 52 & $\begin{array}{c}1550 \\
0\end{array}$ & 1140 & 72 & $<1$ & 7880 & $<1$ & 258.4 & 4320.5 & 716 & -2.12 & -3.34 \\
\hline Rice Hulls & 16.16 & 63.644 & 44.59 & 6.36 & 48.70 & 0.29 & 0.05 & 52 & 650 & 170 & 7880 & 400 & 72 & 7 & $\begin{array}{c}7180 \\
0\end{array}$ & $<1$ & - & - & 751 & -2.69 & - \\
\hline Hardwood & 0.57 & 80.19 & 45.80 & 6.20 & 47.82 & 0.15 & 0.03 & 166 & 1470 & 270 & 1450 & 380 & 71 & $<1$ & 954 & $<1$ & - & - & 781 & -3.07 & -3.18 \\
\hline Bagasse Sachurum & 3.82 & 78.43 & 45.92 & 6.26 & 47.60 & 0.17 & 0.05 & 3100 & 648 & 3700 & 1300 & 440 & 206 & 15 & 8770 & 8 & - & - & 873 & -3.98 & - \\
\hline Pinus Radiata & 0.22 & 79.44 & 46.05 & 6.31 & 47.58 & 0.04 & 0.02 & 170 & 408 & 240 & 738 & 150 & 77 & $<1$ & 910 & $<1$ & - & - & 845 & -3.80 & - \\
\hline Softwood & 0.46 & 76.14 & 46.14 & 6.32 & 46.01 & 1.48 & 0.05 & 220 & 700 & 250 & 997 & 217 & 1590 & $<1$ & 745 & $<1$ & - & - & 781 & -3.08 & - \\
\hline Populus Deltoides & 0.63 & 80.46 & 46.43 & 6.11 & 47.32 & 0.08 & 0.06 & $<10$ & 2450 & 295 & 2360 & 300 & 68 & $<1$ & 644 & $<1$ & 434.3 & 3458.0 & 762 & -2.82 & - \\
\hline $\mathbf{C}_{22} \mathbf{H}_{38} \mathbf{O}_{7}{ }^{a, g}$ & - & - & 63.73 & 9.16 & 26.85 & $<0.01$ & 0.25 & $<100$ & $<100$ & $<100$ & $<100$ & $<100$ & $<100$ & $<100$ & $<100$ & $<50$ & 386.8 & 3504.2 & 912 & -4.51 & -5.05 \\
\hline Beulah (ligA) d & - & - & 73.14 & 4.46 & 20.59 & 1.00 & 0.82 & 6000 & $\begin{array}{c}1800 \\
0\end{array}$ & 6100 & 500 & 5600 & 6600 & 0 & 5000 & 14 & 161.1 & 1320.2 & 730 & -2.44 & -3.83 \\
\hline Polycarbon. Resin a & - & - & 75.48 & 5.69 & 18.81 & $<0.01$ & 0.01 & $<100$ & $<100$ & $<100$ & $<100$ & $<100$ & $<100$ & $<100$ & $<100$ & $<50$ & - & - & 848 & -3.85 & - \\
\hline Phenol-for. Resin a & - & - & 77.76 & 5.96 & 16.22 & 0.05 & $<0.01$ & $<100$ & $<100$ & $<100$ & $<100$ & $<100$ & $<100$ & $<100$ & $<100$ & $<50$ & - & - & 886 & -4.20 & -4.81 \\
\hline Illinois \#6 (hvCb) d & - & - & 78.11 & 5.44 & 9.73 & 1.32 & 5.39 & $\begin{array}{c}1600 \\
0\end{array}$ & 5900 & $\begin{array}{c}2300 \\
0\end{array}$ & 2500 & 800 & 800 & 14 & $\begin{array}{c}3700 \\
0\end{array}$ & 3 & - & - & 823 & -3.59 & -4.46 \\
\hline Rosebud (subB) ${ }^{d}$ & - & - & 78.19 & 4.22 & 15.21 & 1.05 & 1.33 & $\begin{array}{c}1300 \\
0\end{array}$ & $\begin{array}{c}1300 \\
0\end{array}$ & 8500 & 500 & 2600 & 1200 & $<1$ & $\begin{array}{c}2300 \\
0\end{array}$ & 2 & - & - & 765 & -2.90 & - \\
\hline Koonfontain (mvb) & 12.65 & 26.477 & 78.72 & 4.78 & 13.79 & 1.99 & 0.71 & $\begin{array}{c}2260 \\
0\end{array}$ & 6330 & 2630 & 689 & 1940 & 278 & 8 & $\begin{array}{c}2540 \\
0\end{array}$ & 16 & - & - & 904 & -4.08 & - \\
\hline $\mathrm{C}_{30} \mathrm{H}_{18} \mathrm{O}_{4}{ }^{\mathrm{a}, \mathrm{h}}$ & - & - & 79.69 & 4.19 & 16.05 & 0.01 & 0.06 & $<100$ & $<100$ & 300 & $<100$ & $<100$ & 100 & $<100$ & 500 & $<50$ & - & - & 847 & -3.80 & - \\
\hline Fluid Coke & 0.05 & 6.17 & 87.38 & 2.41 & 5.14 & 2.57 & 2.50 & 37 & 102 & 307 & $<10$ & 20 & 136 & 476 & 193 & 477 & - & - & 951 & -4.66 & -5.07 \\
\hline Tire Bits & - & - & 87.63 & 7.57 & 2.55 & 0.39 & 1.87 & 2200 & 2700 & 1500 & 500 & 600 & 400 & 200 & 5000 & $<50$ & - & - & 931 & -4.53 & -4.89 \\
\hline Delayed Coke & 0.05 & 11.048 & 87.80 & 3.96 & 1.41 & 1.43 & 5.40 & 17 & 47 & 213 & $<10$ & 11 & 52 & 198 & 67 & 501 & - & - & 911 & -4.39 & - \\
\hline Pocahontas (lvb) ${ }^{\text {d }}$ & - & - & 89.87 & 4.90 & 3.31 & 1.14 & 0.78 & 6000 & 600 & 7000 & 400 & 800 & 500 & 7 & 7000 & 9 & 113.5 & 5136.2 & 974 & -4.94 & - \\
\hline Lykens Valley (an) $^{\mathrm{d}}$ & - & - & 90.33 & 4.01 & 4.30 & 0.80 & 0.56 & $\begin{array}{c}1800 \\
0\end{array}$ & 400 & 3300 & 4600 & 600 & 200 & 17 & $\begin{array}{c}2900 \\
0\end{array}$ & 21 & 324.8 & 3384.8 & 961 & -4.88 & - \\
\hline Lei Yang (an) & 22.35 & 5.64 & 90.47 & 2.01 & 5.86 & 0.72 & 0.93 & $\begin{array}{c}2780 \\
0\end{array}$ & 6250 & 6900 & 5790 & 1440 & 2730 & 19 & $\begin{array}{c}4670 \\
0\end{array}$ & 41 & 169.8 & 3197.2 & 975 & -5.01 & -5.15 \\
\hline Petroleum Pitch a & - & - & 94.50 & 5.09 & 0.19 & 0.00 & 0.22 & - & - & - & - & - & - & - & - & - & - & - & 974 & -4.97 & - \\
\hline AR-HP Pitch ${ }^{a, e}$ & - & - & 95.13 & 4.87 & 0.00 & 0.00 & 0.00 & - & - & - & - & - & - & - & - & - & 141.1 & 1175.1 & 966 & -4.90 & -5.76 \\
\hline AR-MP Pitch ${ }^{\mathrm{a}, \mathrm{e}}$ & - & - & 95.13 & 4.87 & 0.00 & 0.00 & 0.00 & - & - & - & - & - & - & - & - & - & 132.5 & 5161.6 & 964 & -4.90 & -5.97 \\
\hline Graphite Powder ${ }^{a}$ & - & - & 96.30 & 0.38 & $<0.10$ & 0.87 & 2.45 & 100 & 100 & 500 & $<100$ & $<100$ & $<100$ & 100 & 200 & 280 & - & - & 1052 & -5.54 & -5.55 \\
\hline Graphite Rods ${ }^{a, i}$, & - & - & 100.0 & 0.00 & 0.00 & 0.00 & 0.00 & 1 & 2 & 1 & 0 & 0 & 1 & 0 & 7 & 0 & 5.05 & 6.15 & 1201 & -6.39 & -6.15 \\
\hline \multicolumn{22}{|c|}{ a model materials selected for low amounts of potentially catalytic impurities } \\
\hline \multicolumn{22}{|c|}{ b elemental analyses performed by Huffman Laboratories (Golden, CO) unless otherwise noted } \\
\hline \multicolumn{22}{|c|}{${ }^{\mathrm{c}}$ multi-point BET surface areas of chars $\left(\mathrm{He}, 1 \mathrm{hr}, 700^{\circ} \mathrm{C}\right)$ at $20 \%$ conversion $(\mathrm{daf})$} \\
\hline \multicolumn{22}{|c|}{$\begin{array}{l}\text { d elemental analysis reported by Department of Energy Coal Bank at Penn State data sheets } \\
\text { e synthetic mesophase pitches from naphthalene polymerization, high (HP) and medium (MP) grades; } \\
\text { elemental analysis reported by manufacturer, Mitsubishi Gas Chemical }\end{array}$} \\
\hline \multicolumn{22}{|c|}{${ }^{\mathrm{f}}$ standard reactivity at $500^{\circ} \mathrm{C}$ in air of chars prepared at $700^{\circ} \mathrm{C}$ or $1000^{\circ} \mathrm{C}$, as labeled } \\
\hline \multicolumn{22}{|c|}{ g L-ascorbic acid 6-palmitate } \\
\hline \multicolumn{22}{|c|}{ h 2,2'-dimethyl-1,1'-bianthraquinone } \\
\hline \multicolumn{22}{|c|}{ i elemental composition reported by vendor (Aldrich) } \\
\hline$a n$ & neratur & tes for & the a & & & & & & & & & & & & & & & & & & \\
\hline
\end{tabular}




\section{1-3. Definitions of Standard Reactivity Indices}

The non-isothermal TGA profiles were used to extract standard char reactivities reported here in two different but essentially equivalent forms:

1. Critical temperature values, $T_{c r}$, defined as the temperature at which the combustion rate first equals $0.05 \mathrm{~g} / \mathrm{min}$-g-initial-char. Other researchers have reported $T_{c r}$ values [7] defined in a similar manner as a convenient reactivity index that does not require kinetic assumptions.

2. Reactivity values, $R$, as burning rates in air at a standard reference temperature $\left(T_{\text {ref }}\right)$ of $500^{\circ} \mathrm{C}$, defined as:

$$
R \equiv-\frac{1}{m} \frac{d m}{d t} e^{-\frac{E}{R}\left(1 / T_{r e f}-1 / T\right)}
$$

where $m, d m / d t$, and $T$ are determined at here $20 \%$ conversion, daf. The exponential term brings the raw rates to a common temperature for convenient fuel-to-fuel comparison. This temperature normalization was made using an activation energy of $35 \mathrm{kcal} / \mathrm{mol}(146 \mathrm{~kJ} / \mathrm{mol})$, a typical value for Zone I char oxidation $[2,8,21,22]$. The use of a single activation energy is not a significant disadvantage of this particular reactivity index, because activation energies vary over only a modest range for the low- temperature, disordered chars of interest in this study, and because the standard reference temperature is chosen near the center of the range of actual temperatures, making the temperature correction term inherently small. Indeed there is an excellent correlation between $T_{c r}$ and $R$ as shown in Figure 1, so either index may serve as a valid expression of the relative reactivity of different chars in the sample suite.

\section{1-4. Results.}

Standard reactivities as $T_{c r}$ and/or $R$ values are presented in Table 1 and Figures 2 and 3. Reactivities of the $1000^{\circ} \mathrm{C}$ chars are presented in Figure 3. Surface areas are presented in Table 1 and are cross-plotted against reactivity in Figure 4. The nitrogen and carbon dioxide surface areas of the chars at $20 \%$ conversion are generally similar, indicating the absence of strong molecular sieving effects, which would have complicated the interpretation.

Charpenay et al.[7] use a combustion rate of 0.065 min- 1 to define $T_{\mathrm{cr}}$, but some samples in the present study never achieved rates this high at the chosen heating rate and gas environment 


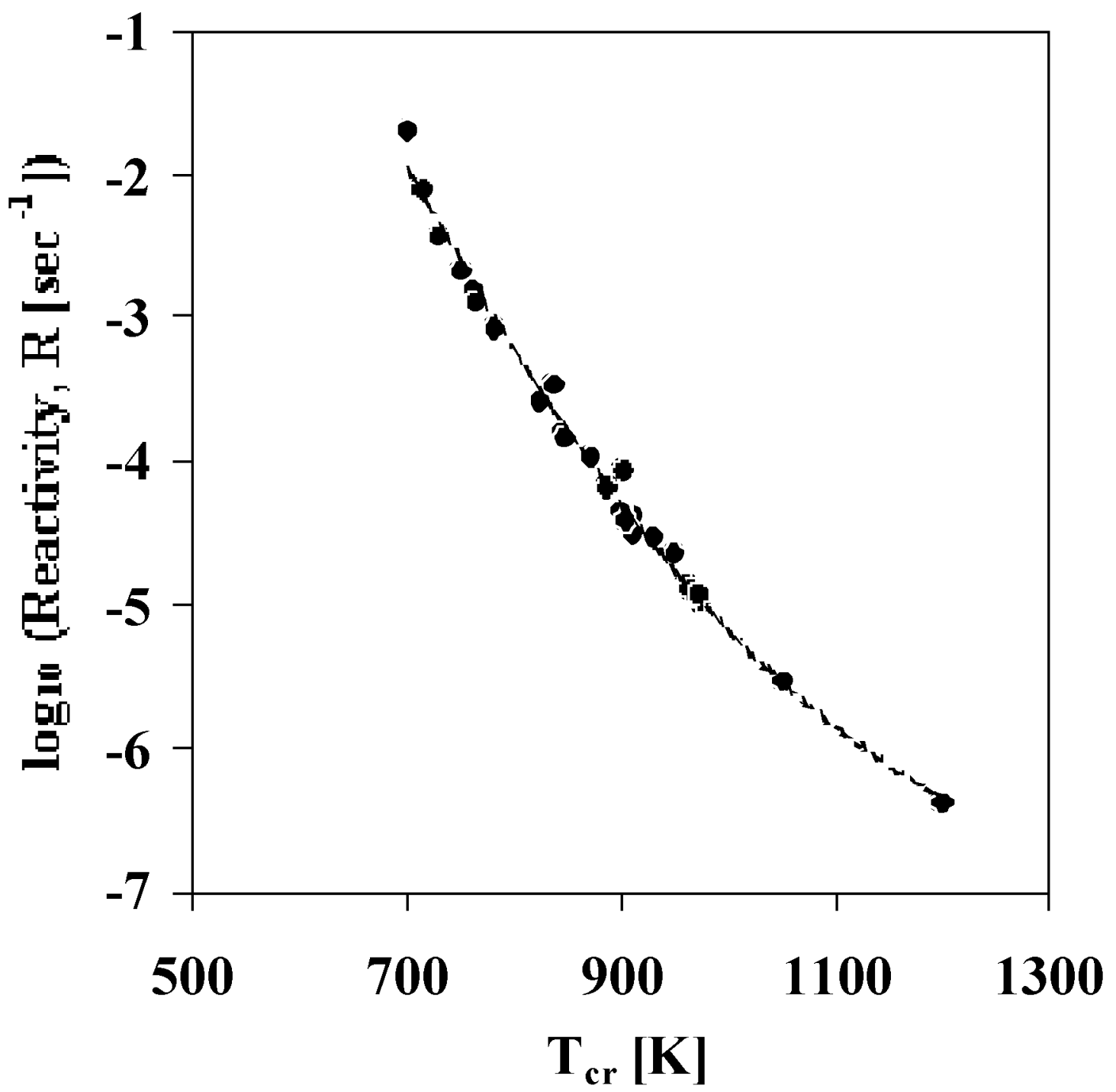

Figure 1. Correlation between the two reactivity indices reported in this work: critical temperatures, $T_{c r}$, and standard reactivities at $500{ }^{\circ} \mathrm{C}$ in air, $R$. For interconversion between the two indices one can use the following empirical expression: $\log _{10} R=-$ $12.6-2.77 \cdot 10^{-2} T_{c r}+9.97 \cdot 10^{-6} T_{c r}^{2}$ 
Trends in reactivity with fuel type are most easily identified using Figure 2, where we see that reactivities of the $700^{\circ} \mathrm{C}$ chars vary by almost 5 orders of magnitude under identical conditions. Considering only the practical solid fuels, the reactivities still span over 3 orders of magnitude, from high-rank coal chars (lowest reactivity) to corn stalk chars (highest reactivity). The $1000^{\circ} \mathrm{C}$ chars in Figure 3 show a similar data pattern, but with just over 3 orders of magnitude total variation in reactivity. A strong correlation is seen between reactivity and carbon (daf) content of the vitrinite-rich coals, as been observed previously [5,6,10]. This trend has no relevance for the biomass fuels, however, which cluster closely in composition (40\%-50\% daf carbon), while their reactivities span almost 3 orders of magnitude. Carbon content is a very poor indicator of biomass reactivity. By analyzing the data in Table 1 it can be further stated that no organic composition variable $(\mathrm{C}, \mathrm{H}, \mathrm{O}, \mathrm{N}, \mathrm{S})$ provides enough information for making even a crude estimate of biomass char reactivity.

It is quite notable in Figure 2 that the model materials, chosen for their lack of inorganic impurities, all have reactivities that lie in a relatively narrow band in the low reactivity region. These non-catalytic char reactivities show almost no composition dependence between $40 \%$ and $80 \%$ carbon (daf), but do fall away above $90 \%$ carbon (daf). Overall, the patterns revealed in Figure 2 strongly suggest that organic composition is secondary to other factors determining reactivity in the char of precursors below $80 \%$ carbon (the majority of practical solid fuels). The next section examines reactivity/property relations in more detail.

\section{1-5. Reactivity / Property Relations}

The goal of this section is to investigate quantitative relationships between reactivity and properties of the parent material, focusing on the larger data set of $700^{\circ} \mathrm{C}$ chars. Statistical software (SPSS Inc.) used for multivariate linear regression revealed positive correlations with statistical significance between reactivity and three properties: wt- $\% \mathrm{~K}, \mathrm{Ca}$, and $\mathrm{Mg}$. In addition a negative correlation was found between reactivity and wt-\%-carbon (daf). A simple linear correlation based on these four variables, however, does not provide an adequate description of the data set. Such blind statistical analyses are easy to perform, but make no use of insights gained from decades of research on combustion and fuel chemistry. Therefore, we pursued a hybrid approach that combines statistical analysis with chemical insights derived from literature data on different fuel classes. 
We begin by expressing the reactivity as a sum of two independent contributions:

$$
R=R_{c a r b}+R_{c a t}
$$

where $R_{\text {carb }}$ represents reaction on non-catalytic (carbon) active sites[23] and $R_{\text {cat }}$ represents reaction on catalytic active sites [22], assumed to be independent, parallel processes. The existence of the narrow model substance band on Figure 2 suggests that variations in $R_{\text {carb }}$ are only a small part of the total reactivity variation for fuels up to up to $80 \%$ carbon (daf) content. We therefore, as an approximation, define a single, non-catalytic baseline reactivity shown in Figure 2 that establishes the model parameter $R_{c a r b}$ as a function of the parent material carbon content. This same line implicitly defines $R_{c a t}$ as the difference between the measured reactivity and $R_{c a r b}$, the non-catalytic baseline value.

The primary challenge is to investigate relations between the catalytic residual, $R_{c a t}$, and fuel properties. Studies involving demineralization and/or direct catalyst addition clearly reveal which elements are intrinsically catalytic for char oxidation: Group I metals, Group II metals, and many transition metals including $\mathrm{V}, \mathrm{Ni}$, and $\mathrm{Fe}$, which have a particular importance in some solid fuels [5,22,24-27]. 


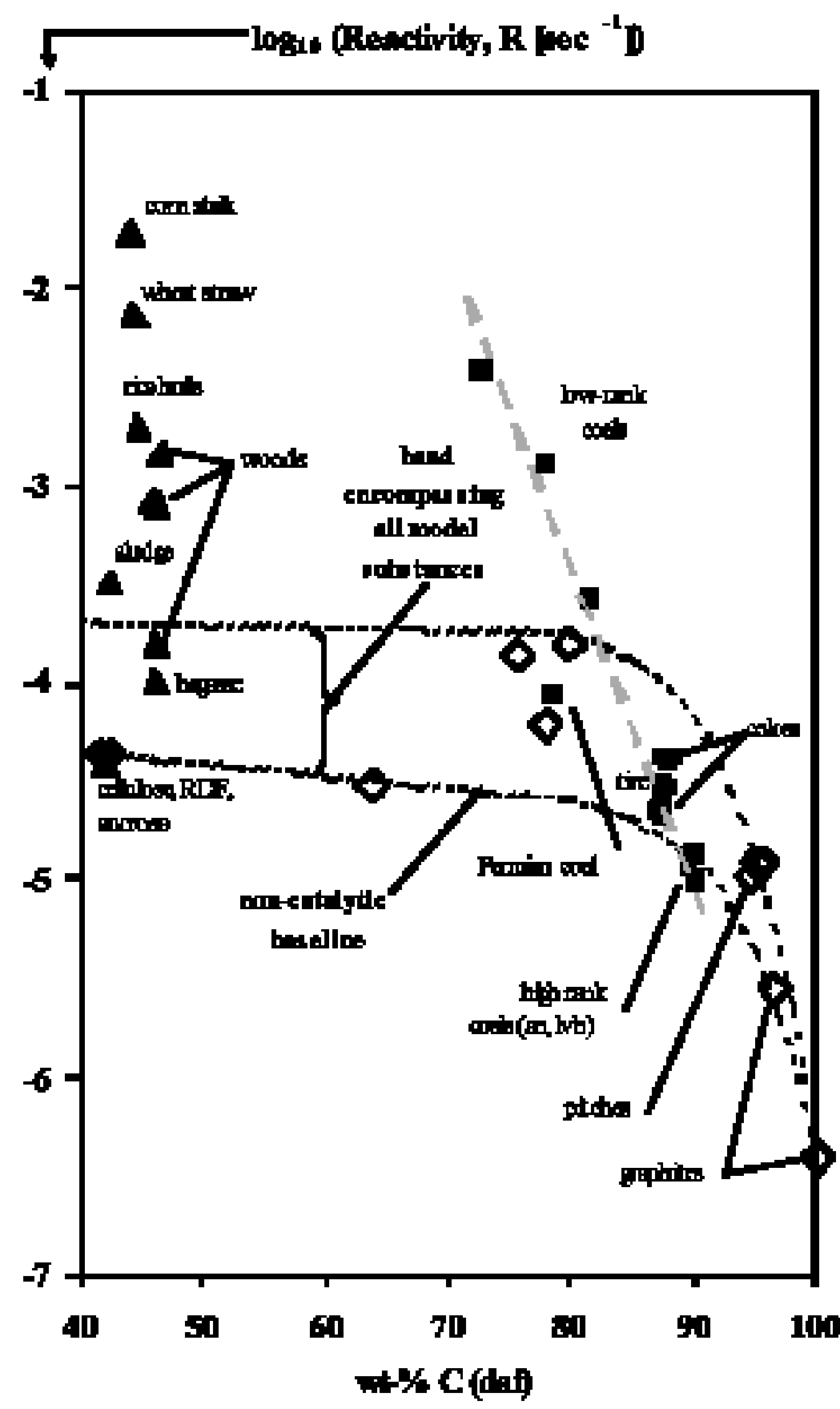

Figure 2. Master plot of measured reactivities for chars prepared at $700{ }^{\circ} \mathrm{C}$ from the 31 precursors plotted as the percentage carbon content of the parent material (daf). The thick dashed line shows a strong correlation between reactivity and rank among vitrinite-rich coals, as reported in other oxidation kinetic studies $[5,6,10]$. The dotted lines define a relatively narrow region that encompasses all of the model materials that are nearly free of potentially catalytic inorganic matter. The lower dotted line is taken as a non-catalytic baseline in the model discussed in the section on reactivity / property relations.

A spliced empirical relation for the non-catalytic baseline is:

$\log _{10} \mathrm{R}_{\text {carb }}=-4.1-6.25 \cdot 10^{-3}(\mathrm{wt}-\% \mathrm{C})$, for wt $-\% \mathrm{C} \leq 80$

$\log _{10} R_{\text {carb }}=-4.52-2.11 \cdot 10^{-7} \exp [0.16(w t-\% C)]$, for wt $-\% C>80$ 


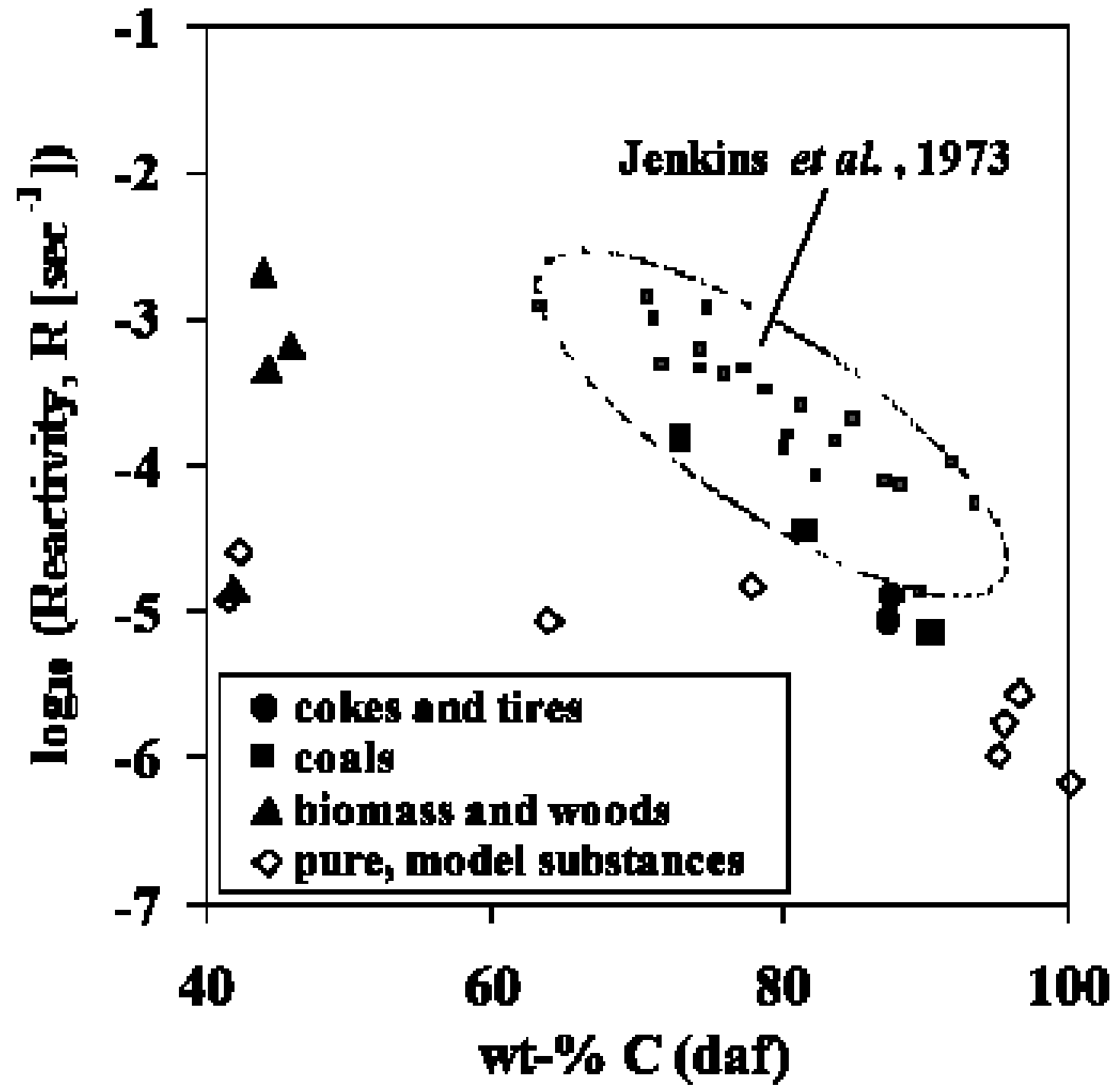

Figure 3. Master plot of measured reactivities for chars prepared at $1000{ }^{\circ} \mathrm{C}$ from a 17 sample subset of the 31-sample suite. The absolute reactivities are generally lower, but the fuel-to-fuel differences fall in a pattern very similar to the $700{ }^{\circ} \mathrm{C}$ chars in Figure 2. Literature data from Jenkins et al.[5] on coal chars prepared under similar conditions is shown for comparison. 

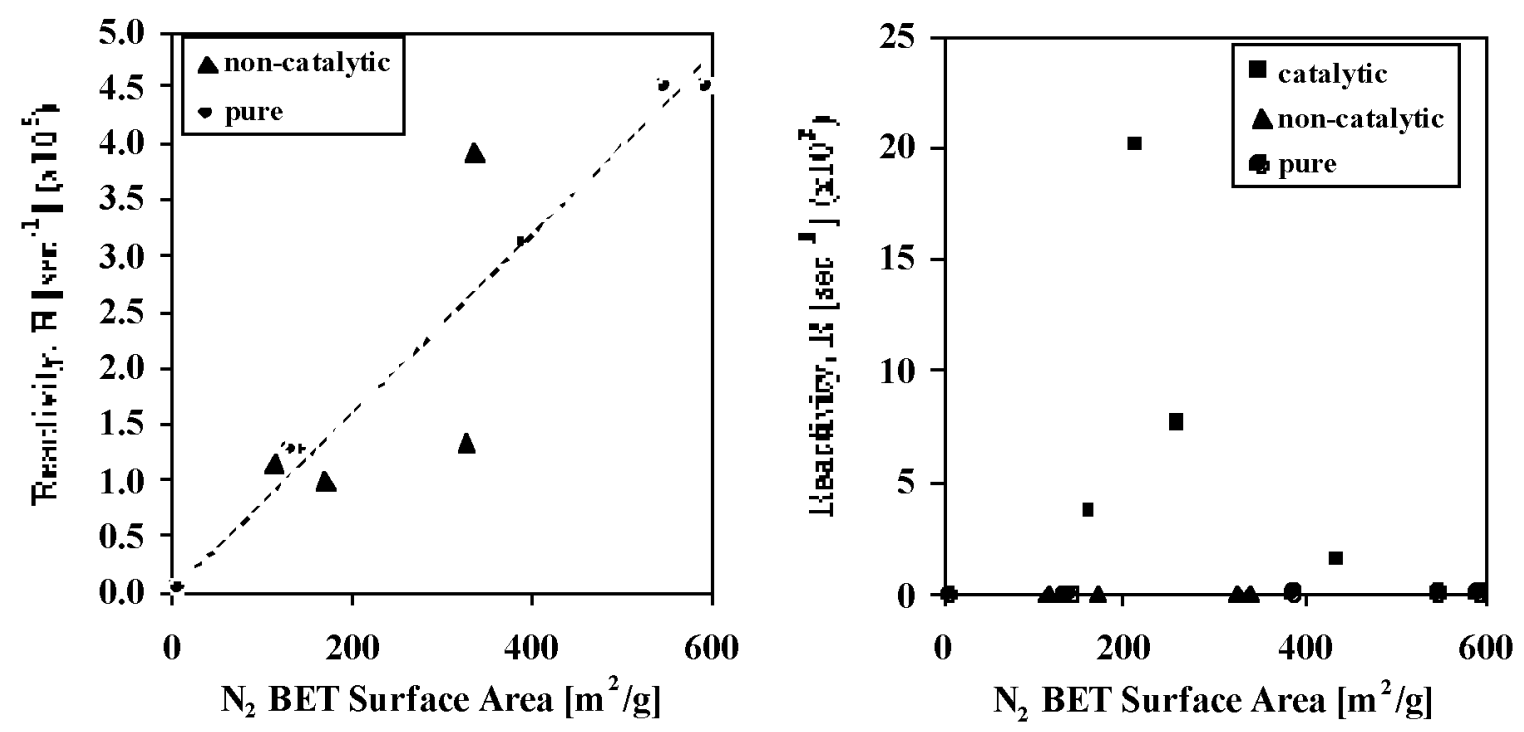

Figure 4. Cross plot of reactivity vs. total char surface area $\left(\mathrm{N}_{2} \mathrm{BET}\right)$ for pure and noncatalytic materials (left hand side) and for all samples (right hand side). Circles (pure materials) are the nearly-inorganic-free model substances from Table 1; Triangles (non-catalytic materials) are samples containing significant amounts of inorganic matter, but predicted by dispersion arguments to react in a primarily non-catalytic mode (see section on reactivity/ property relations).

Another key consideration is catalyst dispersion, or particle size, which is expected to vary greatly across the spectrum of solid fuels. Although dispersion is continuum variable, one can consider two important limiting cases: (1) granular dispersion- particulate matter of supramicron dimension arising from extraneous matter or bulk additives in the fuels, and (2) nanophase dispersion - finely dispersed particulate matter of submicron dimensions in chars originating from nanophase or atomically dispersed metals in the parent materials that have partially sintered during carbonization [22]. This highly active material may originate as dissolved salts in plant water, as cations exchanged on carboxylic sites, or as organometallic compounds with essential function (e.g. chlorophyll, porphyrins). Granular material has low catalytic activity by virtue of its low surface area [28], which suggests the relation:

$$
R_{\text {cat }}=\alpha\left(K_{\text {nano }}\right)+\beta\left(C a_{\text {nano }}+M g_{\text {nano }}\right)+\gamma\left(V_{\text {nano }}\right)
$$


Here $M_{\text {nano }}$ indicates the wt-fraction (ppmw) of the nano-dispersed or atomically dispersed form of catalytic metal, $M$, present in the parent fuel, and $\alpha, \beta$, and $\gamma$ are specific activity coefficients to be determined from statistical analysis of the data. Although $\mathrm{Na}, \mathrm{Ni}$, and $\mathrm{Fe}$ are known catalysts for char oxidation[26,29], they are not observed to make statistically significant contributions to reactivity in this particular sample set and thus cannot be included in Eq. [3]. The alkaline earth metals are grouped together because our statistical analysis revealed a strong cross-correlation, making any attempt to distinguish the separate effects of $\mathrm{Ca}$ and $\mathrm{Mg}$ statistically meaningless. Studies employing metal addition have reported similar specific activities for $\mathrm{Ca}$ and $\mathrm{Mg}$ [26], so their linear combination here with equal weight is a useful approximation.

Before $\alpha, \beta$, and $\gamma$ can be determined, specific rules are needed for estimating the degree of catalyst dispersion in the various fuel classes. In coals, mineral matter is a combination of granular material and atomically dispersed material [30,31], with the major source of atomically dispersed matter in the form of cations exchanged on carboxylic sites [22,31]. The compilation of literature data in Figure 5 shows the carboxylic site density is strongly dependent on coal rank. For the hybrid chemical/statistical model we use the correlation shown in that figure to estimate carboxylic site density from wt-\% carbon (daf) and carry out a stoichiometric calculation to determine what fraction of the $\mathrm{K}, \mathrm{Ca}$, and $\mathrm{Mg}$ in the sample is needed to saturate those $-\mathrm{COOH}$ sites. This simple two-step correlative technique gives a reasonable estimate of $\mathrm{K}_{\text {nano }}, \mathrm{Ca}_{\text {nano, }}$, and $M g_{\text {nano }}$ for use in Eq. [3].

Dispersion of metals in biomass is also a mixture of granular and atomically dispersed forms [32-35]. In most plants, however, potassium salts are essential nutrients, and a high fraction of the potassium (80-90\%) is either water soluble or ion-exchangeable [32,33,35,36]. Most calcium also tends to be water soluble or ion-exchangeable, indicative of high dispersion. An exception is sugar cane bagasse, which is washed during processing and has lost soluble salts [33,35]. For purposes of the model we take the group I and II metals in biomass to be finely dispersed with the exception of bagasse in which the remaining matter is taken to be primarily granular. For the non-biomass alternate fuels, we take the inorganic components in tire fuel to be granular, while the vanadium in cokes is taken to be nano-dispersed, since it originates as atomically dispersed material within porphyrin structures in petroleum [37]. 
The preceding set of dispersion rules, along with Eqns. [2] and [3], the baseline function in Figure 2, and the carboxylic correlation in Figure 5, define the hybrid chemical/statistical model. Application of the model to our data set leads to the final correlation and the optimal leastsquares values of $\alpha, \beta$, and $\gamma$ shown in Figure 6. The now complete hybrid model provides a link between parent fuel elemental composition and char reactivity at $500^{\circ} \mathrm{C}$ in air for chars prepared at $700^{\circ} \mathrm{C}$ from arbitrary and diverse organic precursors.

It is clear from this analysis that catalysis plays a dominant role in the low-temperature reactivity of chars prepared at $700^{\circ} \mathrm{C}$. Through examination of the data patterns in Figure 3 , this same conclusion appears to hold for the chars prepared at $1000^{\circ} \mathrm{C}$. Using the final values of $\alpha, \beta$, and $\gamma$ as sensitivity coefficients, it can be stated that as little as 44 ppmw of nano-dispersed potassium or 270 ppmw of nano-dispersed $\mathrm{Ca}$ or $\mathrm{Mg}$ is sufficient for the catalytic component of reactivity to exceed the non-catalytic component for materials below $80 \mathrm{wt}$-\%-carbon (daf). With these sensitivities it is difficult to rule out catalytic effects in all but the most pure materials. Indeed, the ICP sensitivity limits for some of the nearly pure model materials are 100 ppmw, so residual catalysis may even be important for some of these compounds, such as $\mathrm{C}_{30} \mathrm{H}_{18} \mathrm{O}_{4}$ and polycarbonate resin, which lie in the upper region of the model substance band in Figure 2. Among the practical solid fuels, only the very highest rank coals (with no $-\mathrm{COOH}$ sites) are adequately approximated as non-catalytic. Previous studies employing acid demineralization have also suggested that catalytic effects are significant for most coals[5], although questions have often been raised about collateral effects of strong acids on the organic matrix. The present work reaches the same conclusion by statistical inference from reactivity data without the need for aggressive mineral solvents. 


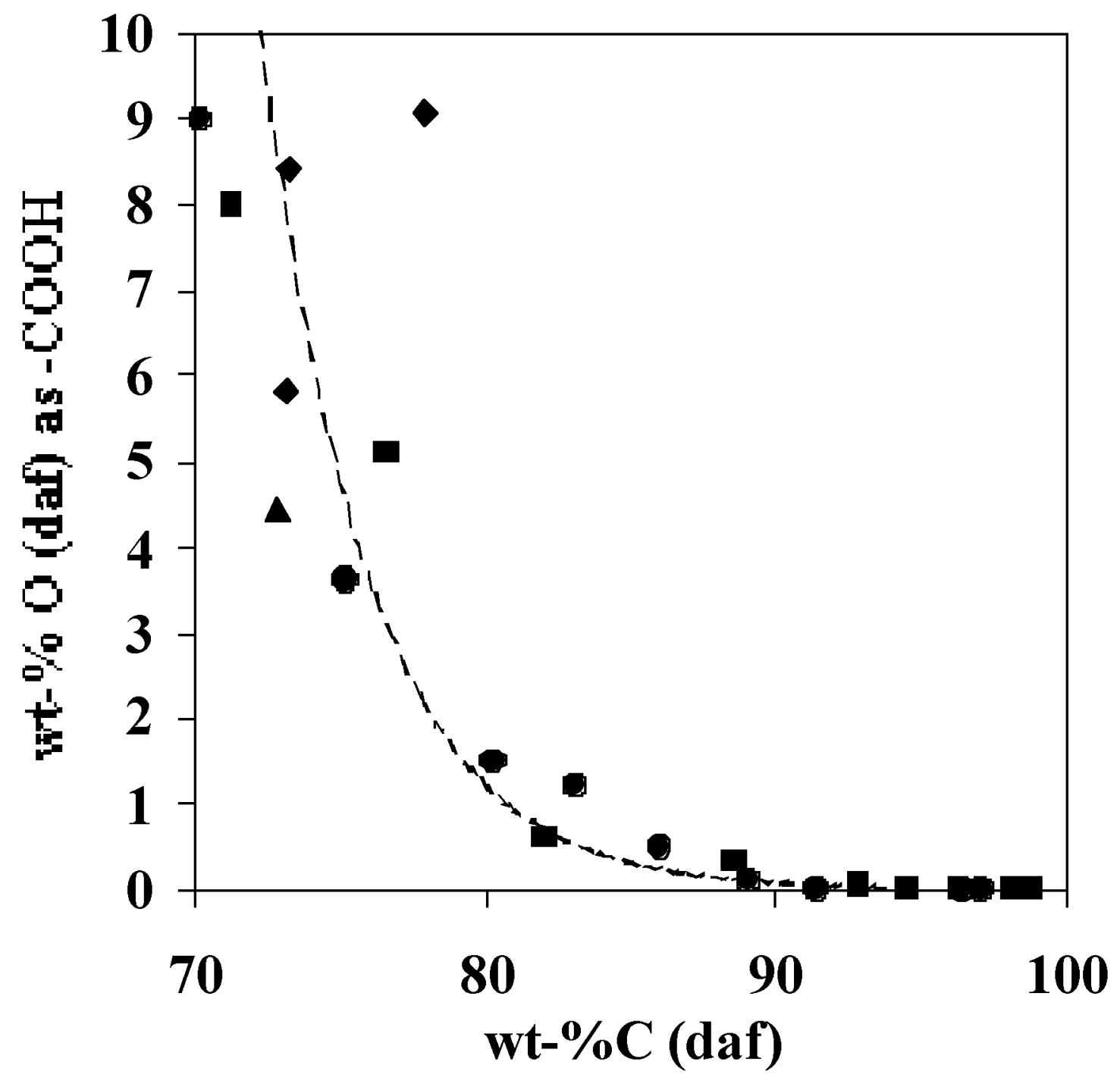

Figure 5. Compilation of literature data on the abundance of carboxylic groups in coals of various rank. Sources: circles are data from Ihnatowicz in [38], diamonds are data from Morgan and Jenkins [31], squares are data from Blom in [38], and triangles are data from Otake and Walker [39]. The fitted curve for use in the hybrid chemical/statistical model is: $(\mathrm{wt}-\% \mathrm{O}$ as $-\mathrm{COOH})=3.051 \cdot 10^{-9} \mathrm{exp}[-0.2706 \mathrm{wt}-$ $\% \mathrm{C}$ (daf)] for wt-\% C $<90$. Above $90 \mathrm{wt}-\% \mathrm{C},-\mathrm{COOH}$ site density is taken to be 0 in the model. 


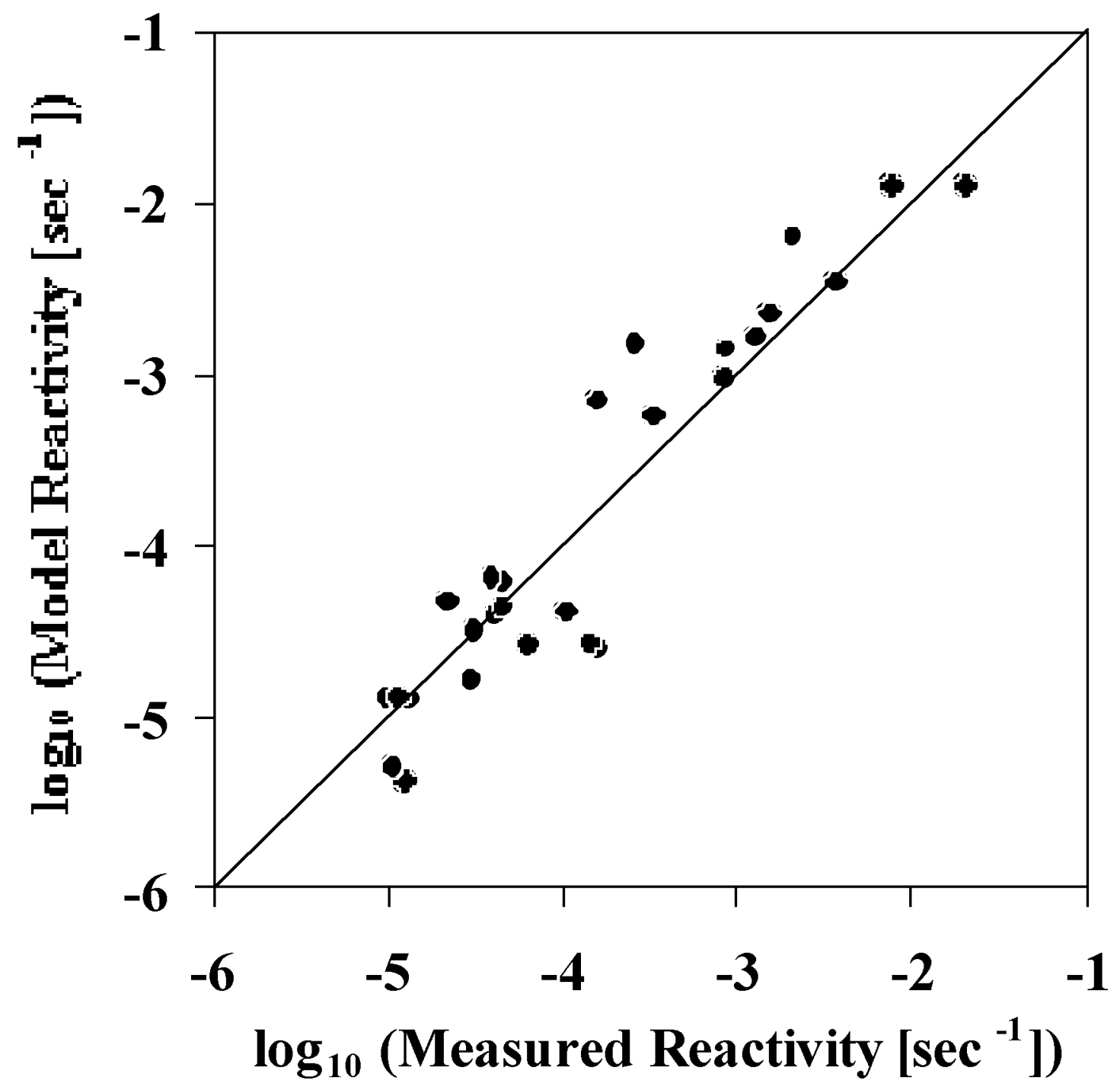

Figure 6. Comparison of measured reactivities with reactivities given by the hybrid chemical/statistical model. The plot contains every solid fuel and model material listed in Table 1 except graphites (which cannot be meaningfully described as 700 ${ }^{\circ} \mathrm{C}$ chars) and the Permian southern hemisphere coal (for which Figure 6 does not contain relevant data on carboxylic sites). The model reactivity is equal to:

$$
R=R_{\text {carb }}+\alpha\left(K_{\text {nano }}\right)+\beta\left(C a_{\text {nano }}+M g_{\text {nano }}\right)+\gamma\left(V_{\text {nano }}\right)
$$

where $R_{\text {carb }}$ is the baseline function in Figure 2, $\alpha=7.9 \cdot 10^{-7}, \beta=1.3 \cdot 10^{-7}$, and $\gamma$ $=3.1 \cdot 10^{-8}$, where the nano or atomically dispersed metals are measured in ppmw of the parent fuel. 


\section{1-6. Conclusions}

1. Char combustion reactivities at $500{ }^{\circ} \mathrm{C}$ in air from a diverse set of fuels and organic model compounds vary over 4 orders of magnitude when chars are prepared at $700{ }^{\circ} \mathrm{C}$ and over 3 orders of magnitude when chars are prepared at $1000{ }^{\circ} \mathrm{C}$. Reactivities correlate poorly with organic elemental composition and poorly with char surface area.

2. Specially-acquired model materials with minute amounts of inorganic matter exhibit low reactivities that fall in a narrow band as a function of wt- $\%$ carbon. Reactivities in this sample subset correlate reasonably well with total char surface area.

3. A hybrid chemical/statistical model explains most of the observed reactivity variation based on four variables: the amounts of nano-dispersed $\mathrm{K}$, nanodispersed $(\mathrm{Ca}+\mathrm{Mg})$, elemental carbon (wt-\% daf), and nano-dispersed vanadium, listed in decreasing order of importance. Catalytic effects play a very significant role in the oxidation of most practical solid fuel chars. Some degree of reactivity estimation is possible using only elemental analyses of parent fuels, but only if correlative techniques make use of the existing body of knowledge on the origin, form and dispersion of inorganic matter in various fuel classes. 


\subsection{High Pressure Coal Combustion Studies at BYU.}

\section{2-1. Summary.}

During the past year, research has focused primarily on renovation of the BYU high pressure drop tube reactor (HPDT). This work has included design and testing of a flat-flameburner that can be operated at high pressure. A high-temperature, high-pressure gas profile has been achieved within this high-pressure flat-flame burner (HP-FFB). Detailed descriptions of the design and testing of the HP-FFB are given in this report. In addition, continued char reactivity experiments in the high pressure thermogravimetric analyzer (HP-TGA) have been performed on chars produced at different pressures in the HPDT. Results of the HP-TGA reactivity studies on a high-volatile A bituminous (Pitt \#8) char are that intrinsic char activation energy increases with pyrolysis pressure, and that the oxygen order is roughly 0.9 . These results are different than previous research on chars produced at atmospheric pressure. These new data show that the rate constant decreases with increasing pyrolysis pressure. However, the hydrogen content of the new chars produced at elevated pressures was fairly high ( 2 wt. \%, daf), and char samples produced at higher temperatures are desired.

\section{2-2. Development of High-Pressure Flat-Flame-Burner.}

The BYU high pressure drop tube (HPDT) facility has been used in high pressure combustion research by several researchers [40,41]. In particular, Monson performed reactivity measurements as a function of pressure and temperature on a char that had been prepared at high temperature at atmospheric pressure in a flat-flame burner. One of the goals of the current set of experiments is to measure the pressure-dependent char reactivities at the pressure at which the chars were formed.

The HPDT facility is electrically heated to control the reactor temperature. A schematic of this system is shown in Figure 7. Pulverized fuel particles are entrained in nitrogen and fed to the reactor at a small flow rate $(\sim 1 \mathrm{~g} / \mathrm{hr})$ in order to study single particle behavior. The current heating system is based on nichrome wire heaters, which have a maximum operating range of $1473 \mathrm{~K}$. The pressure vessel for this reactor is rated for operation at pressures up to 25 atm. During the period 2000-2001, the HPDT reactor was fixed and renovated, including upgrading gaskets, flow controllers, and the pressure controller. 


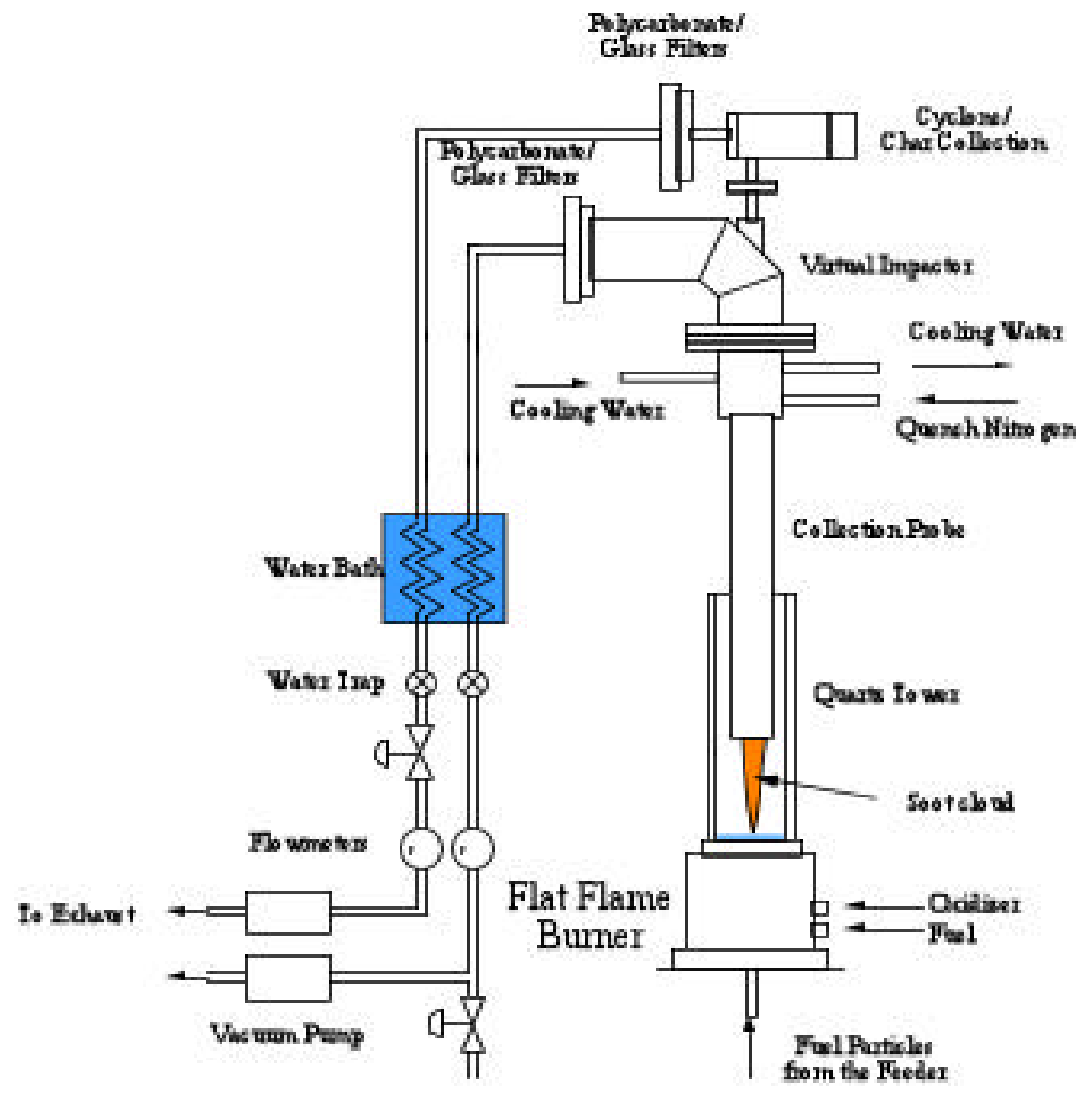

Figure 7. Schematic of the high pressure drop tube reactor (HPDT).

Preliminary experiments in the electrically-heated HPDT demonstrated that significant heat loss occurred at elevated pressures. It is suspected that the insulation used in the reactor walls changes thermal conductivity with increases pressures. Figure 8 shows temperature profiles in the HPDT at four pressures. Even at atmospheric pressure, the highest temperature is only about $1300 \mathrm{~K}$. Analysis of char pyrolyzed at this condition indicates pyrolysis reaction is not completed; the hydrogen content of the final char was about $2 \mathrm{wt} . \%$ on a daf basis. In contrast, chars produced at atmospheric pressure in the flat-flame burner facility exhibited hydrogen contents of about $0.5 \mathrm{wt}$. \% daf. It is therefore thought that the temperatures in the HPDT were too low to produce adequate chars that would be representative of the initial stages of an industrial pressurized combustion of gasification system. 


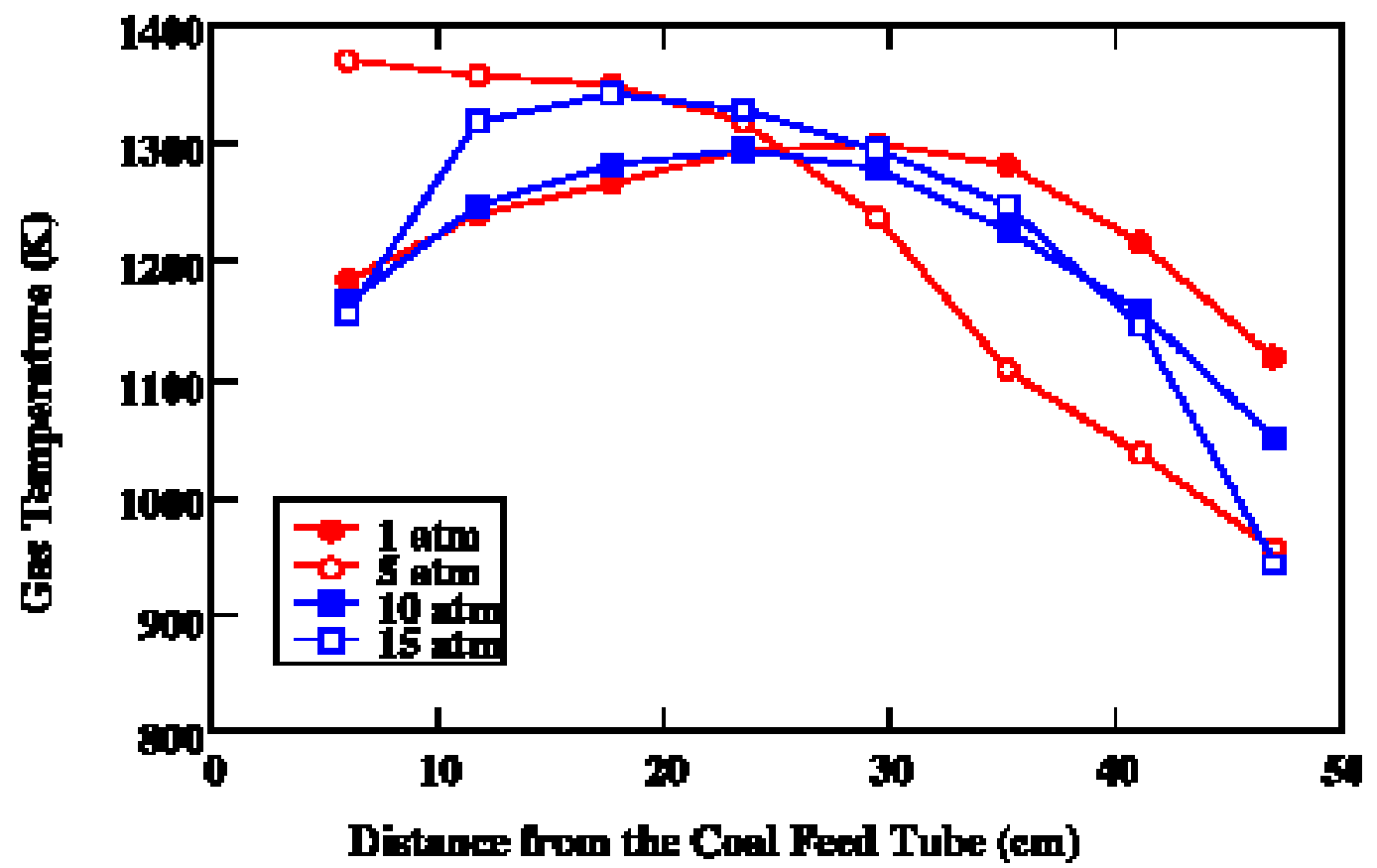

Figure 8. Measured temperatures for Condition 1 in the BYU High Pressure Drop Tube reactor.

This temperature restriction in the HPDT became motivation to design of a high pressure flat-flame-burner (HP-FFB), as shown schematically in Figure 9. The initial design was to use a one-inch diameter FFB, inserted in a manner to replace the original coal feed tube in the HPDT. The flat-flame burner uses the hot products of methane combustion to heat entrained coal particles. The FFB more closely approximates a true pulverized coal combustion environment, since pyrolysis occurs in post combustion gases rather than in pure nitrogen or other inert gas. Pyrolysis temperature in a FFB can be adjusted by changing the equivalence ratio or fuel composition. Residence time can be changed by raising or lowering the burner relative to the collection probe. Maximum particle heating rates in the flat flame reactor are about $10^{5} \mathrm{~K} / \mathrm{s}$. Coal particles are injected to the center axis of a round cross section quartz tube, within which the combustion products from a laminar, fuel-rich, high-temperature, and methane-air flat flame. Char oxidation experiments are performed in a fuel-lean environment, while pyrolysis experiments can be performed with little or no post-flame $\mathrm{O}_{2}$. Coal particles are entrained by a nitrogen stream, and the velocities of the entrainment gas are set to match the cold gas velocities at the top of the flat flame burner. This minimizes turbulence at the point of injection so that the particles flow down the center axis of the drop tube with minimal dispersion. 


\section{Schematic of High Pressure Flat Flame Burner}

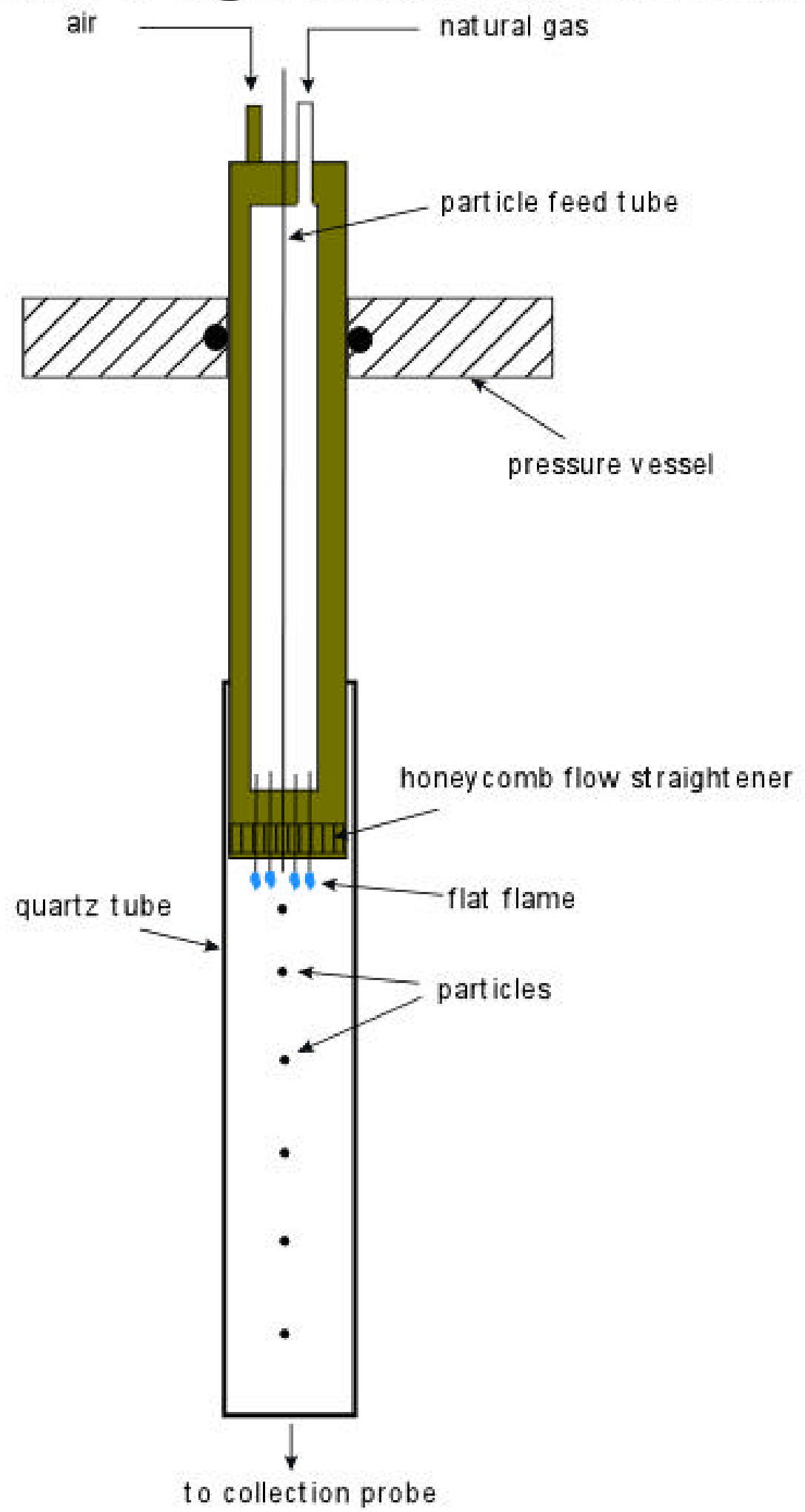

Figure 9. Schematic of the High Pressure Flat Flame Burner (HP-FFB). 
During the first quarter, a one inch diameter FFB was designed and manufactured. From February, 2002 to May, 2002, this one inch diameter FFB was tested at high pressure. A highvoltage ignition system was installed. Due to safety concerns with the high pressure combustion, an automatic fuel-shutoff valve was installed. The shutoff valve is controlled by a controller that monitors the temperature measured by a thermocouple installed close to the flame. If the flame goes out, and the temperature drops below the set point, the controller will close the valve, shutting off methane flow to avoid accumulation of methane inside furnace chamber.

Because this burner is down-fired and did not have a water cooling system, it was found the burner tip became so hot that coal particles were pyrolyzed before leaving the feed tube, resulting in a clogged feed tube. Another problem was that the heat load for the one-inch burner is too small to heat the entire reactor. Also, because methane is used as a fuel, steam condenses in the char collection system, which is undesirable.

To solve these problems, a two-inch diameter burner was designed and tested in the period from June, 2002 to January, 2003. A water cooling system effectively prevented the burner tip from getting too hot, which significantly reduced clogging in the feed tube. In addition, the original heater from the HPDT was retained and is currently used in conjunction with the HPFFB to achieve a high-temperature profile. It was found that the heated quartz muffle tube in the HP-FFB was sufficient to autoignite the methane flame at temperatures of $1200 \mathrm{~K}$ without using an igniter.

Temperature profiles at three reactor pressures are shown in Figure 10. The decrease in reactor temperature as a function of distance from the burner is due to heat losses. These temperature profiles are adequate to produce high heating rate chars with low hydrogen contents. High temperature, coal pyrolysis experiments at elevated pressures will commence in the next quarter. The first experiments will be performed on Pittsburgh \#8 coal and Wyodak subbituminous coal at $1300^{\circ} \mathrm{C}$, with pressures ranging from 1 to10 atm. 


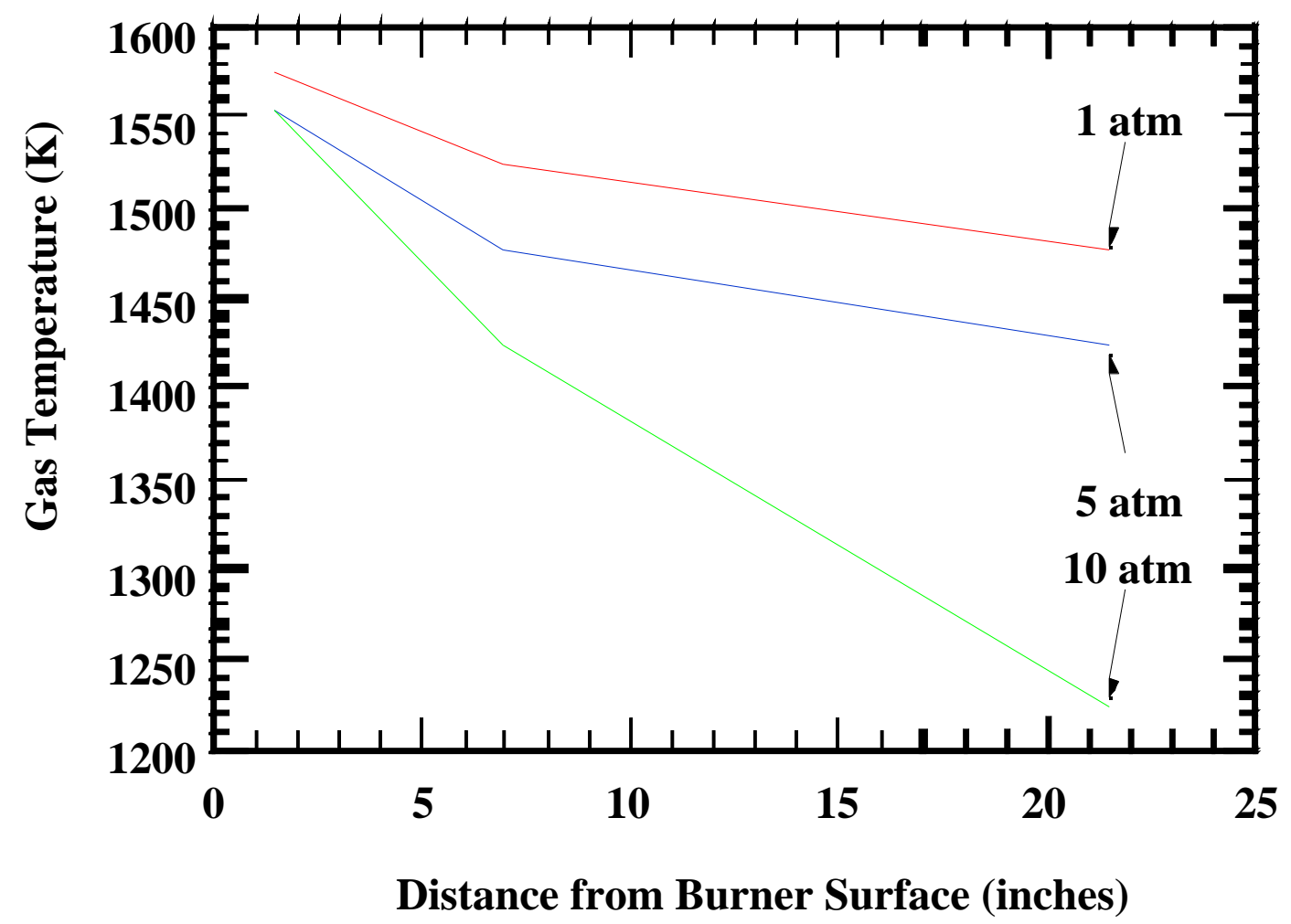

Figure 10. Measured temperatures for Condition 1 in the BYU High Pressure Drop Tube reactor.

\section{2-3. Oxidation Kinetics of HPDT Char.}

Preliminary coal char preparation experiments were conducted using a Pittsburgh \#8 coal in 2001. Char samples from each pressure condition were analyzed for elemental composition (CHNS) and compared with the analysis of a char prepared in a flat-flame burner at atmospheric pressure as reported early. After these tests, a series of High-Pressure-TGA (HPTGA) tests were processed on these char samples.

Figure 11 shows typical TGA test data; usually a $2-4 \mathrm{mg}$ sample is used in each test. Data are analyzed based on the following global reactivity equation:

$$
\frac{1}{m} \frac{d m}{d t}=k P_{O 2}^{n}
$$

Reaction activation energy can be calculated by changing reaction temperature, reaction order $n$ can be found by changing oxygen pressure. Since all of HPTGA tests were performed at low temperature, mass transfer effects are minimal. Total pressures in the HP-TGA were set to be 
the same as the pressures at which each char was formed. This should give a better representation of the true char reactivity as a function of pressure.

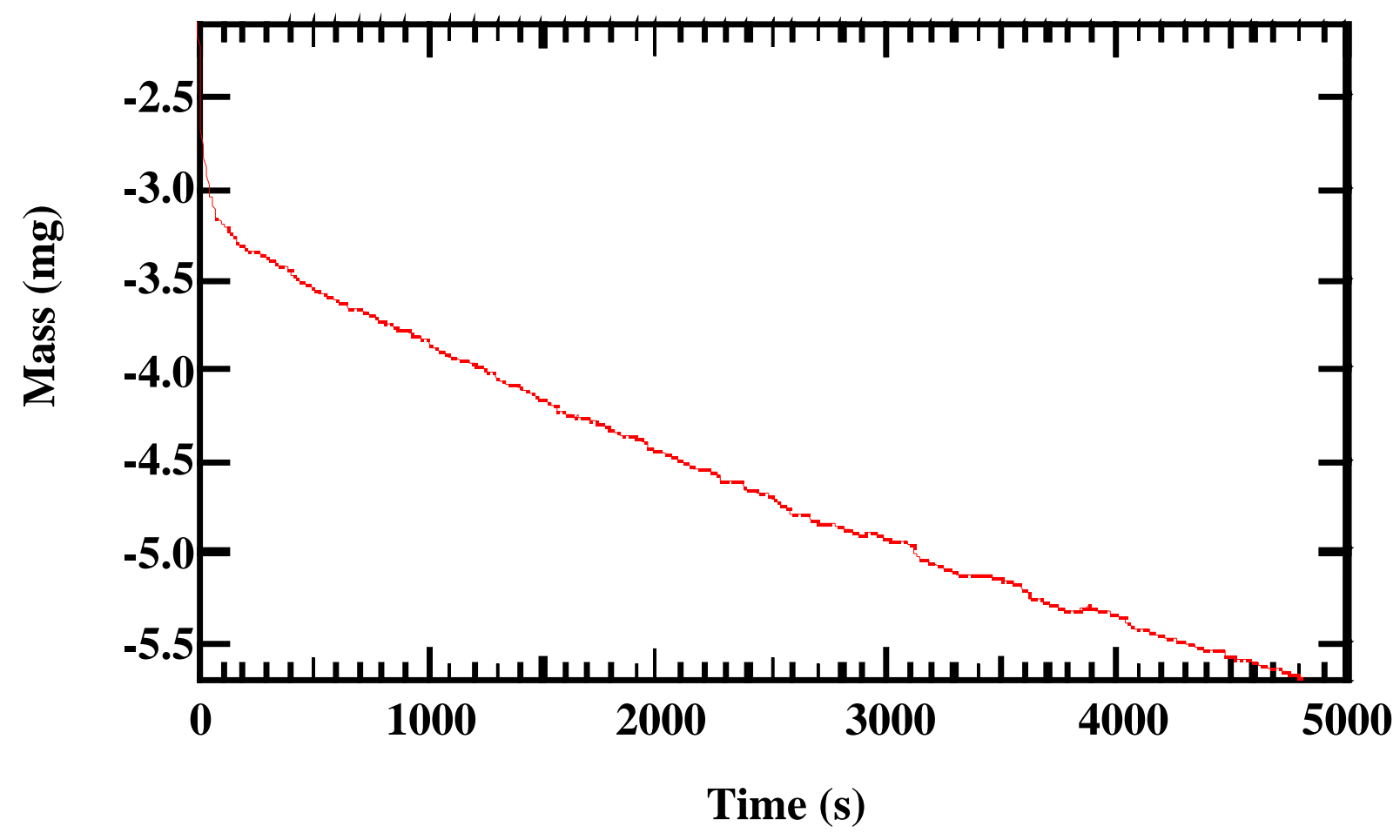

Figure 11. Typical TGA data (4.3 mg Pittsburgh \#8 char, $\left.5 \mathrm{~atm}, 20 \% \mathrm{O}_{2}, 375^{\circ} \mathrm{C}\right)$.

Figure 12 shows results from the HP-TGA analysis of the HPDT char, indicating that intrinsic rate constants decreased with increasing pyrolysis pressure. Some early observations are that chars produced at different pyrolysis pressures have different apparent reaction rates, but similar intrinsic rates. However pyrolysis pressure may have a significant influence on char morphology. High pressure pyrolysis tends to form more porous char particles than at atmospheric pressure. The morphology contributes to the difference in apparent reactivity. Preliminary data indicate that intrinsic reactivities of chars formed at different pressures seem similar [42]; further data are needed to determine if this result is true at different temperatures and heating rates. Further studies are needed to determine the effects of high pyrolysis temperatures $(>1673 \mathrm{~K})$ on the properties of char formed at different pressures. 


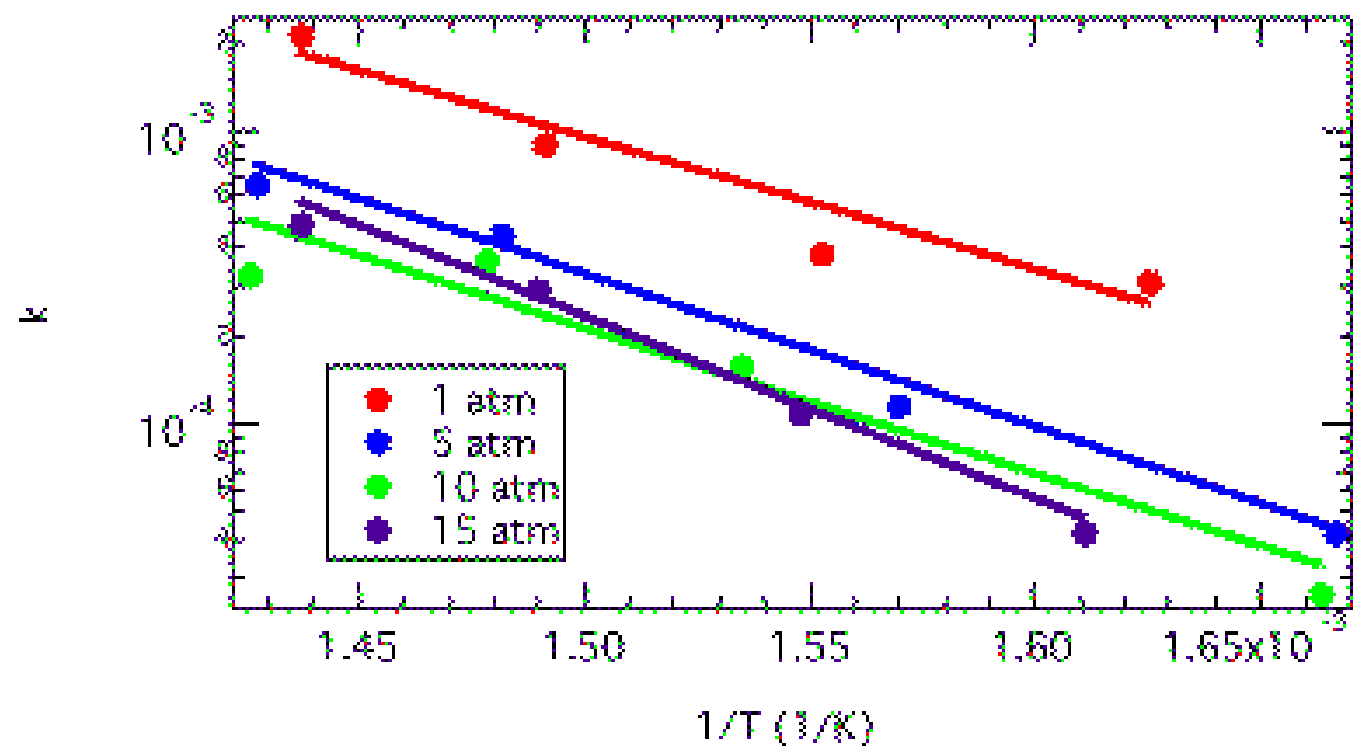

Figure 12. Intrinsic rate constants decreased with increasing pressure.

The reaction orders determined from the HP-TGA experiments on the HPDT chars (see Figure 13) change slightly with increasing pressure. The calculated reaction order is 0.9 , which is higher compared to other data $(n=0.7)$ [43], obtained from char produced at atmospheric pressure in a FFB.

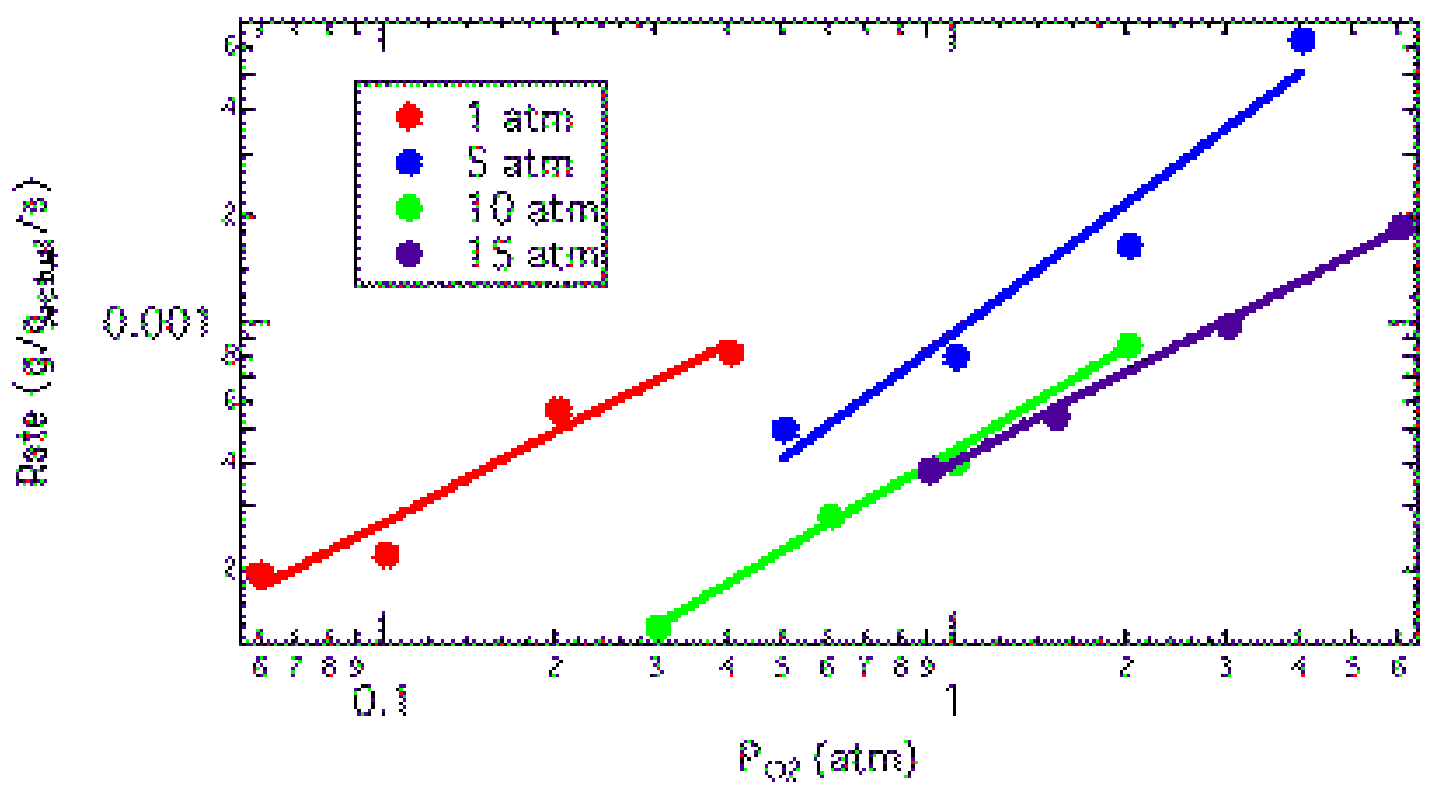

Figure 13. Slight changes in reaction order with increasing pressure 


\section{2-4. Future Work}

During the coming year, high pressure, high temperature chars will be made in the HP-FFB. It is anticipated that chars from five different coals will be made and analyzed. HPTGA tests will be performed on each char to determine intrinsic reactivity at the pressure at which the chars were formed. Char morphology will also be determined and compared with chars formed at lower heating rates by other organizations such as SRI and the CRC in Australia. 


\section{REFERENCES}

1. Essenhigh, R.H., in Chemistry of Coal Utilization, Second Supplementary Volume (M.A. Elliot, ed.), Wiley, New York, 1981, p. 1153.

2. Smith, I.W., Fuel 57:409 (1978).

3. Miura, K., Hashimoto, K., and Silveston, P.L., Fuel 68:1461 (1989).

4. Williams, A., Pourkashanian, M., Jones, J.M., Proc. Comb. Inst. 28:2141 (2000).

5. Jenkins, R.G., Nandi, S.P., and Walker Jr., P. L., Fuel 52:288 (1973).

6. Fung, D.P.C., and Kim, S.D., Fuel 63:1197 (1984).

7. Charpenay, S., Serio, M.A., and Solomon, P.R., Proc. Comb. Inst. 24:1189 (1992).

8. Zolin, A., Jensen, A., Pederson, L.S., Dam-Johansen, K., and Tørslev, P., Energy Fuels 12:268 (1998).

9. Field, M.A., Combust. Flame, 14:237 (1970).

10. Hurt, R.H., and Mitchell, R.E., Proc. Comb. Inst. 24:1243 (1992).

11. Luo, M., and Stanmore, B., Fuel71:1074 (1992).

12. Werther, J., and Ogada, T., Progress in Energy and Combustion Science 25:55 (1999).

13. Zheng, G., and Kozinski, J.A., Fuel 79:181 (2000).

14. Zolin, A., Jensen, A., Jensen, P.A., Frandsen, F., Dam-Johansen, K., Energy and Fuels 15:1110 (2001).

15. Devi, T.G., and Kannan, M.P., Energy \& Fuels 15:583 (2001).

16. Ganesh, A., Grover, P.D., and Iyer, P.V.R., Fuel71:889 (1992).

17. Di Blasi, C., Buonanno, F., and Branca, C., Carbon 37:1227 (1999).

18. Marcilla, A., García-García, S., Asensio, M., and Conesa, J.A., Carbon 38:429 (2000).

19. Aarna, I., and Suuberg, E.M., Proc. Comb. Inst. 27:2933 (1998).

20. Adams, K.E., Glasson, D.R., and Jayaweera, S.A.A., Carbon 27:95 (1989).

21. Suuberg, E.M., Wojtowicz, M., Calo, J.M., Proc. Comb. Inst. 24:79 (1988).

22. Radovic, L.R., Walker, Jr., P.L., and Jenkins, R.G., Fuel 62:209 (1983).

23. Radovic, L.R., Walker, P.L.Jr., Jenkins, R.G. Fuel, 62:849 (1983).

24. Cope, R.F., Arrington, C.B., and Hecker, W.C., Energy \& Fuels 8:1095 (1994). 
25. Haykiri-Açma, H., Ersoy-Meriçboyu, A., and Küçükbayrak, S., Thermochimica Acta 362:131 (2000).

26. McKee, D.W., in Chemistry and Physics of Carbon (Volume 16) (P.L. Walker, Jr. and P.A. Thrower, Eds.), Marcel Dekker, New York, 1981, p.1.

27. Devi, T.G., and Kannan, M.P., Fuel 77:1825 (1998).

28. Tomita, A., Mahajan, O.P., Walker,Jr. P.L., ACS Fuel Chem. Preps, 22:4 (1977).

29. Zhang, D.-K., and Poeze, A., Proc. Comb. Inst. 28:2337 (2000).

30. Baxter, L.L., Mitchell, R.E., and Fletcher, T.H., Combustion and Flame 108:494 (1997).

31. Morgan, M.E., Jenkins, R.G., and Walker, Jr., P.L., Fuel 60:189 (1981).

32. Epstein, E., Mineral Nutrition of Plants: Principles and Perspectives, Wiley and Sons, New York, 1972.

33. Jenkins, B.M., Baxter, L.L., Miles, Jr., T.R., and Miles, T.R., Fuel Processing Technology 54:17 (1998).

34. Dayton, D.C., Jenkins, B.M., Turn, S.Q., Bakker, R.R., Williams, R.B., Belle-Oudry, D., and Hill, L.M., Energy and Fuels 13:860 (1999).

35. Baxter, L.L., Miles, T.R., Miles, Jr., T.R., Jenkins, B.M., Milne, T., Dayton, D., Bryers, R.W., and Oden L., Fuel Processing Technology 54:47 (1998).

36. Jensen,P.A., Frandsen,F.J., Dam-Johansen,K., and Sander,B., Energy Fuels 14:1280 (2000).

37. Marquez, N., Ysambertt, F., De La Cruz, C., Anal. Chim. Acta 395:343 (1999).

38. Krevelen, D.W and Schuyer J., Coal Science: Aspects of Coal Combustion, Elsevier, Princeton, NJ, 1957, p. 217.

39. Otake, Y., and Walker, Jr., P.L., Fuel 72:139 (1993).

40. Mathias, J. A., "High Pressure Oxidation Rates for Large Particles", M.S. Thesis, Mechanical Eng. Dept., Brigham Young University, 1996.

41. Monson, C. R., G. J. Germane, A. U. Blackham and L. D. Smoot, "Char Oxidation at Elevated Pressure," Combustion and Flame, 100: 669-683 (1995).

42. Roberts, D. G., "Intrinsic reaction Kinetics of Coal Chars with Oxygen, Carbon Dioxide and Steam at Elevated Pressures", Dept. of Chemical Engineering, University of Newcastle, 2000.

43. Hecker, W.C., M.P. Madsen, R.S.Michael, J.W. Allen, R.J. Sawaya and T. H. Fletcher, "High Pressure Intrinsic Oxidation Kinetics of Two Coal Chars," Submitted to Energy and Fuels, (2002). 